\title{
Recovering PHAs from mixed microbial biomass: using non-ionic surfactants as a pretreatment step
}

\author{
Bianca Colombo ${ }^{1}$, Joana Pereira ${ }^{2}$, Margarida Martins ${ }^{2}$, Mario A. Torres-Acosta ${ }^{3}$, Ana C. \\ R. V. Dias ${ }^{4}$, Paulo C. Lemos ${ }^{5}$, Sónia P. M. Ventura², Giorgio Eisele ${ }^{6}$, Anna Alekseeva ${ }^{6}$, \\ Fabrizio Adani ${ }^{1}$, Luísa S. Serafim ${ }^{2 *}$
}

${ }^{1}$ DISAA - Gruppo Ricicla labs - Department of Agricultural and Environmental Sciences - Production, Landscape, Agroenergy, Università degli Studi di Milano, Milan, Italy; ${ }^{2}$ CICECO - Aveiro Institute of Materials, Department of Chemistry, University of Aveiro, 3810-193 Aveiro, Portugal; ${ }^{3}$ The Advanced Centre for Biochemical Engineering, Department of Biochemical Engineering, University College London, Torrington Place, London, WC1E 6BT, UK; ${ }^{4}$ CESAM - Centre for Environmental and Marine Studies, Department of Environment and Planning, University of Aveiro, 3810-193 Aveiro, Portugal; ${ }^{5}$ LAQVREQUIMTE, Chemistry Department, Faculty of Science and Technology, University Nova of Lisbon, 2829516 Caparica, Portugal; 'Centro Alta Tecnologia "Istituto di Ricerche Chimiche e Biochimiche G. Ronzoni" Srl, Via Colombo 81, 20133 Milan, Italy

*Corresponding author - Luísa S. Serafim, E-mail: luisa.serafim@ua.pt

\begin{abstract}
Polyhydroxyalkanoates (PHAs) are biodegradable plastics of microbial origin, whose biodegradability and thermochemical properties make them greener alternatives to conventional plastics. Despite their high industrial potential, the PHAs' high production costs still hinder their application. Mixed microbial biomass combined with agroindustrial wastes are being used to strategically reduce these costs. However, it is still necessary to optimize the downstream processing, where the extraction process amounts to $30-50 \%$ of the total costs. Conventional processes apply chlorinated solvents to recover PHAs from microbial biomass but cannot be implemented industrially due to environmental regulations. Alternative solvents, with good results of purity and recovery yields, usually have a negative impact on the molecular weight of the final polymer. In this work, the addition of a pre-treatment based on non-ionic surfactants (Tween ${ }^{\circledR} 20$, Brij $^{\circledR}$ L4, and Triton $^{\mathrm{TM}} \mathrm{X}$-114) to extract PHA from mixed microbial biomass selected on fermented agro-industrial wastes was investigated. The best results were obtained with Tween ${ }^{\circledR} 20$ allowing for an increase in $50 \%$ compared with the use of dimethylcarbonate without any pre-treatment (from $38.4 \pm 0.8 \%$ to $53 \pm 2 \%$ ) and very close to those obtained with chloroform (63\%). The extracted polymer was analysed and characterized, revealing a PHA of high purity ( $>90 \%$ ) and low molecular weight loss (under $24 \%$ ). Additionally, a material-focused economic and a carbon footprint analysis were performed and supported the selection of the method as one of the cheapest options and with the lowest carbon footprint.
\end{abstract}

Keywords: Polyhydroxyalkanoates, Surfactants, Extraction, Mixed Microbial Biomass, Economic and Environmental Analysis 


\section{INTRODUCTION}

Polyhydroxyalkanoates (PHAs) are biopolyesters synthesized by many bacterial species as intracellular reserves of carbon and energy. Their biodegradability and thermochemical properties make them suitable as greener alternatives to conventional plastics [1]. Despite their high industrial potential, PHAs are considered biopolymers of high production costs, which continue to be a limiting step on their application.

Mixed microbial biomass, instead of pure cultures, and agro-industrial wastes, as substrates, are being used to strategically reduce the production costs. However, the downstream processing still represents the major drawback of the process, with the extraction process amounting to $30-50 \%$ of the total costs [2,3]. Downstream strategies consist mainly on the extraction of PHAs granules from bacterial cells, in some cases preceded by a pre-treatment to improve the recovery yield. Then, a step of purification may be introduced to meet the purity required by the final application. In this sense, the ideal method should lead to a high purity and recovery level at the lowest cost [4].

Early, processes resorted to chlorinated solvents to recover PHAs from microbial biomass $[4,5]$. Those disrupt the lipid portion of the cell wall and allow for PHA solubilisation resulting in high extraction yields with little damage to polymer chains. However, environmental restrictions limited their industrial use, imposing the urgency to search for more benign and less toxic alternatives $[2,6]$.

The extraction procedures currently adopted on pure microbial strains can be divided into two main classes: PHAs solubilisation/recovery with organic solvents and the dissolution of Non-PHA Cell Mass (NPCM) with chemicals (i.e. acids, alkalis, and surfactants) or enzymes [7-10]. However, both approaches present several disadvantages $[7,11,12]$. Alternative solvents (e.g. propylene carbonate, ethyl acetate, methyl isobutyl ketone) were reported with good results of purity and recovery yields, but with a negative impact on the molecular weight of the final polymer, which can limit the polymers' applications. Moreover, other benign alternatives were tested, such as ionic liquids and supercritical fluids, but some are still too costly to represent a valid substitute $[2,8,13]$.

While some of the issues have been solved for pure cultures even using surfactants $[14,15]$, the mixed microbial biomass pose an extra challenge due to their heterogeneity and complex cell structure, more resistant to hydrolysis. Besides, different substrates and processes of production led to different types of microbial biomass, meaning that an extraction process developed for a particular microbial biomass may not be efficient for all cases. For these reasons, mixed microbial biomass are often overlooked and research on extraction procedures is still scarce [8].

Samorì et al. (2015) reported an innovative PHA extraction procedure from mixed microbial biomass by proposing the use of dimethyl carbonate (DMC), a non-polar solvent with good miscibility with water, readily biodegradable, and non-toxic [16]. DMC resulted in a recovery yield of $63 \%$, after a two-step extraction was performed, and provided a polymer with good quality and a purity of $95 \%$. In order to increase the extraction yield and develop a process that can also be applied to mixed microbial biomass more resistant to dissolution, a pre-treatment step should be considered.

The NPCM dissolution with chemicals began with nonselective dissolution systems, mainly represented by alkalis (i.e. sodium hydroxide - $\mathrm{NaOH}$ and sodium hypochlorite $\mathrm{NaClO}$ ) and acids digestion, which, if too concentrated, can lead to degradation of both NPCM and PHAs, thus reducing the recovery yield and lowering PHAs molecular weight $[9,10,17]$. These methods were then replaced by selective dissolution chemicals, including anionic (i.e. sodium dodecyl sulphate - SDS), cationic (i.e. hexadecyltrimethylammonium bromide - CTAB), non-ionic surfactants (i.e. Tween 20 and 
Triton X-100) and proteolytic enzymes. These surfactants can be directly applied to the wet microbial biomass, avoiding the expensive dewatering step, not affecting the properties of the final product. On the other hand, they should be used in high concentrations and result in a low extraction purity, often requiring a final purification step $[2,7,18]$. Table 1 presents an overview of the reported PHA extraction procedures for mixed biomass and their impact in the polymer characteristics.

Non-ionic surfactants, the focus of this work, are amphiphilic molecules whose effect on cell aggregation and membrane permeability was already reported $[19,20]$. Their use as extraction agents in biological processes is also a recurrent topic in literature $[19,21,22]$, with some works already reporting its use for PHA extraction from pure cultures $[23,24]$. In this work, this uncharged class of surfactants was selected, since they were reported as better solvents and/or disrupting agents for some particular cells like brown macroalgae and microalgae [25]. Consequently, higher yields of extraction with lower contents of surfactant could be expected, as well as the decrease in the economic and environmental impacts of the final process.

This work tested the application of a microbial biomass pre-treatment using non-ionic surfactants of low cost, Tween $^{\circledR} 20$, Brij $^{\circledR} L 4$, and $\operatorname{Triton}^{\text {TM }} \mathrm{X}-114$ as a way of increasing the efficiency of the extraction of PHAs with DMC for the mixed microbial consortia investigated. The microbial biomass used was selected on fermented dairy wastes. Furthermore, the results of the average molecular weight and thermo-chemical characterization of the extracted PHA were evaluated to assess the impact of the extraction procedure on the polymer characteristics. The process that resulted in the highest polymer yield, higher purity and lower molecular weight loss will be proposed for a future optimisation envisaging industrial implementation. Moreover, both a materialfocused economic analysis and an environmental analysis considering the carbon footprint of the process were performed. The objective was to determine which pretreatment option was the cheapest, how different parameters could affect the production costs, and also, which process option corresponded to the lowest carbon footprint.

\section{MATERIALS AND METHODS}

\subsection{Materials}

\subsubsection{Microbial biomass}

To develop the PHAs extraction procedure, a PHAs-rich microbial biomass produced following the same protocol as in Colombo et al. (2019) was used [26]. The cells were collected from an accumulation reactor fed with fermented dairy wastes. After being collected, the microbial biomass was centrifuged at $10,000 \mathrm{~g}$ for $15 \mathrm{~min}$ at room temperature, the supernatant was discarded, and the pellet washed three times with 0.9 $\%$ of $\mathrm{NaCl}$ solution. The final pellet was freeze-dried and kept in a desiccator for further procedures.

\subsubsection{Reagents}

The compounds tested on the PHAs extraction from the microbial biomass were the polyoxyethylene sorbitan monolaurate $\left(\right.$ Tween $^{\circledR} 20, \mathrm{Mw}$ (molecular weight) $=1228$, hydrophilic-lipophilic balance; HLB = 16.7 [27]), polyethylene glycol dodecyl ether (Brij ${ }^{\circledR}$ L4, $, M w=362, H L B=10$ [28]), dimethyl carbonate (DMC), chloroform, all supplied by Sigma-Aldrich (Darmstadt, Germany), and polyethylene glycol tert-octylphenyl ether 
(Triton ${ }^{\text {TM }}$ X-114, Mw = 537, HLB 12.3 [29]) supplied by Acros Organics, Thermo Fisher Scientific (Waltham, MA, USA). The ethanol used to wash the biomass was supplied by VWR Chemicals (purity $\geq 96 \%$ ). Tetrahydrofuran (THF, purity $\geq 96 \%$ ) for liquid chromatography LiChrosolv ${ }^{\circledR}$ and $\mathrm{P}(\mathrm{HB}-\mathrm{HV})$ standards were provided by Sigma-Aldrich (Darmstadt, Germany). For extraction/transesterification prior to Gas Chromatography analysis pure chloroform, methanol, heptadecane and sulphuric acid used were provided by Sigma-Aldrich.

\subsection{Methods}

\subsubsection{Solubilisation tests}

PHAs solubility tests were performed to minimize the risk of losing PHAs by solubilisation during the microbial biomass digestion with the non-ionic surfactants. Moreover, this was also helpful to understand the mechanism behind the use of nonionic surfactants. These tests were performed by mixing $0.5 \mathrm{~g}$ of industrial $\mathrm{P}$ (3HB) (SigmaAldrich, Darmstadt, Germany) with $5 \mathrm{~mL}$ of surfactant (Tween ${ }^{\mathrm{TM}} 20$, Triton $^{\mathrm{TM}}{ }^{\mathrm{X}} \mathrm{X}-114$, Brij ${ }^{\circledR}$ L4) at $60^{\circ} \mathrm{C}$ for $4 \mathrm{~h}$, with gentle mixing. The liquid fractions were then analysed by FT-IR and compared to the spectra of each surfactant to evaluate the possible presence/solubilisation of the biopolymer.

\subsubsection{Extraction procedure}

In this work, PHAs were extracted from microbial biomass starting with a pretreatment using non-ionic surfactants previous to PHA extraction with DMC. Thus, a twostep approach was developed. The first step consisted in a selective dissolution of the non-PHAs cell mass (NPCM) by using non-ionic surfactants, followed by a second step corresponding to the PHAs extraction using DMC in the same conditions proposed in literature [2].

The pre-treatment step was carried out at $60^{\circ} \mathrm{C}$ and with orbital stirring set at $80 \mathrm{rpm}$ for $4 \mathrm{~h}$ of contact between cells and the non-ionic surfactant, accordingly to results of preliminary assays (data not shown). To optimize the pre-treatment step, three non-ionic surfactants were tested, two solid-liquid ratios (S/L ratios) and two non-ionic surfactant concentrations. All three variables were combined resulting in a total of 12 tests, performed in duplicate.

Then, the pre-treated microbial biomass was centrifuged at $47432 \mathrm{~g}$ for $30 \mathrm{~min}$ at 25 ${ }^{\circ} \mathrm{C}$, the supernatant was discarded and the pellet was washed three times following the sequence: $5 \mathrm{~mL}$ of deionized water, $5 \mathrm{~mL}$ of ethanol $(70 \% \mathrm{v} / \mathrm{v})$ and $5 \mathrm{~mL}$ of deionized water. After discarding the supernatant, the pellet was left to dissolve in DMC by keeping the same conditions reported by Samorì et al. (2015), namely $1 \mathrm{~h}$ of contact at $90^{\circ} \mathrm{C}$, with a $\mathrm{S} / \mathrm{L}$ ratio of $0.025 \mathrm{~g}_{\text {cells. }} \mathrm{mL}^{-1} \mathrm{DMC}$ solvent. Finally, the mixture was vacuum filtrated with glass microfiber membranes $(0.45 \mu \mathrm{m}$ of porosity), and the DMC was left to evaporate. The dry weight of the obtained extract was measured by drying the samples in an oven at $30^{\circ} \mathrm{C}$ until constant weight.

For all tests, the biopolymer recovery yield (Eq. 1) was calculated and a statistical analysis was performed to define the best conditions to be adopted in the pre-treatment step. After defining the optimal conditions for the pre-treatment of the microbial biomass with the best non-ionic surfactant, a higher $\mathrm{S} / \mathrm{L}$ ratio $\left(0.075 \mathrm{~g}_{\text {cells. }} \mathrm{mL}^{-1}{ }_{\mathrm{DMC}}\right.$ solvent $)$ in the further step with DMC was tested and the data compared with the results obtained in the literature [2]. All tests were performed in duplicate being the recovery yields (Eq. 1 ) and respective deviations determined. 


$$
\text { PHA recovery }(\%)=\frac{P H A \text { recovered }(g)}{P H A \text { initial }(g)} \times 100
$$

For the optimized process, the extracts of biopolymer produced were analysed in terms of purity by thermogravimetric analysis (TGA) according to the procedure reported in the literature [30] and the molecular weight by a HP-SEC/TDA. The final process developed was applied to perform a final extraction in a larger scale, ending with the characterization of PHA by Dynamic Light Scattering (DSC), TGA and Gas Chromatography (GC).

\subsubsection{Control tests}

To evaluate the effectiveness of the optimized extraction procedure, two control tests were performed using DMC and chloroform, respectively. For the test with DMC, the microbial biomass samples were incubated with DMC $\left(90^{\circ} \mathrm{C}\right.$ for $1 \mathrm{~h}$ with a S/L ratio of $0.025 \mathrm{~g}_{\text {cells. }} \cdot \mathrm{mL}^{-1} \mathrm{DMC}$ solvent) further centrifuged at $4000 \mathrm{rpm}$ for $1 \mathrm{~min}$ and then filtered with polypropylene membrane filters of $0.45 \mu \mathrm{m}$ porosity [2]. For the test with chloroform, microbial biomass samples were suspended in $\mathrm{CHCl}_{3}\left(38^{\circ} \mathrm{C}\right.$ for 3 days with a $\mathrm{S} / \mathrm{L}$ ratio of $0.025 \mathrm{~g}_{\text {cells. }} \mathrm{mL}^{-1}$ solvent) and were then filtered with polypropylene membrane filters of 0.45 $\mu \mathrm{m}$ of porosity [31]. For both cases, the polymer was recovered by solvent evaporation.

\subsubsection{Statistics}

PHAs recovery yield data were statistically analysed by one-way ANOVA to compare means with a level of significant difference set at $p$-value $<0.05$; the Duncan test was used as the method to compare means. All statistical analyses were performed by using SPSS software (SPSS Statistics v. 25.0, IBM, Armonk, NY, USA).

\subsubsection{Analytical Methods}

2.2.5.1. High-performance size exclusion chromatography combined with a triple detector array (HP-SEC/TDA)

The PHA molecular weight was determined by high-performance size exclusion chromatography combined with a triple detector array (HP-SEC/TDA) measurement. The HP-SEC equipment consisted of a Viscotek system (Malvern Instrument Ltd, Malvern, UK) equipped with a Knauer HPLC pump K501, and a Biotech Degasi GPC degassing device. The detector system was a Viscotek mod. 302 Triple Detector Array (TDA), which is composed by Laser Light Scattering detector $\left(90^{\circ}\right.$ and $7^{\circ}$; wavelength $\left.670 \mathrm{~nm}\right)$, Refractive index (RI) detector (cell volume of $12 \mu \mathrm{L}$; light emitting diode (LED) at $660 \mathrm{~nm}$ wavelength) and viscosimeter detector (four capillaries with a differential Wheatstone bridge configuration). A PLgel $20 \mu \mathrm{m}$ MIXED A column $(7.5 \times 300 \mathrm{~mm})$ was used. THF was used as mobile phase at a flow rate of $1 \mathrm{~mL} \cdot \mathrm{min}^{-1}$. Columns, injector, and detectors were maintained at $35{ }^{\circ} \mathrm{C}$. Samples were dissolved in chloroform at concentration $2-6 \mathrm{mg} / \mathrm{mL}$ and filtered on a $0.2 \mu \mathrm{m}$ membrane before injection. The injection volume was $100 \mu \mathrm{L}$. All the samples were analyzed in duplicate.

The system was calibrated with the polystyrene (PS) narrow standard of known Mw, polydispersity and intrinsic viscosity (Malvern PolyCAL PS standards - 105kDa). A differential refractive index increment $(\mathrm{dn} / \mathrm{dc})$ value of 0.047 was used for further calculations [32].

\subsubsection{Gas chromatography $(G C)$}


The determination of PHAs cell content and PHAs composition were performed by GC adapted from Moita and Lemos (2012) [33]. Two mg of microbial biomass were incubated with $1 \mathrm{~mL}$ of a solution of chloroform with heptadecane as internal standard and $1 \mathrm{~mL}$ of acidic methanol solution $\left(20 \% \mathrm{H}_{2} \mathrm{SO}_{4}\right)$, at $100{ }^{\circ} \mathrm{C}$ for $3.5 \mathrm{~h}$. After cooling, $0.5 \mathrm{~mL}$ of water were added for extraction. The chloroform phase was collected and molecular sieves $(0.3$ $\mathrm{mm}$ ) were added to ensure water adsorption. $2 \mu \mathrm{L}$ of the obtained solution were injected into a gas chromatograph coupled to a Flame Ionization Detector (GC-FID, Bruker 400GC). A Restek Stabilwax-MS capillary column was used with hydrogen as the carrier gas $(50 \mathrm{kPa})$ using a splitless injection mode at $240^{\circ} \mathrm{C}$. The oven temperature program was defined as follows: $40{ }^{\circ} \mathrm{C}$; then $20^{\circ} \mathrm{C} \cdot \mathrm{min}^{-1}$ until $100{ }^{\circ} \mathrm{C}$; then $3^{\circ} \mathrm{C} \cdot \mathrm{min}^{-1}$ until $155^{\circ} \mathrm{C}$; and finally, $20{ }^{\circ} \mathrm{C} \cdot \mathrm{min}^{-1}$ until $220{ }^{\circ} \mathrm{C}$. The detector temperature was set at $230{ }^{\circ} \mathrm{C}$. Hydroxybutyrate (HB) and hydroxyvalerate (HV) concentrations were calculated using standards of a commercial P(HB-HV) $(88 \% / 12 \%$, Sigma-Aldrich) and corrected using a heptadecane internal standard. The calibration curve for $\mathrm{HB}$ ranged from $0.0688 \mathrm{mg} . \mathrm{mL}^{-}$ ${ }^{1}$ to $4.40 \mathrm{mg} \cdot \mathrm{mL}^{-1}$ and for $\mathrm{HV}$, from $0.00938 \mathrm{mg} \cdot \mathrm{mL}^{-1}$ to $0.600 \mathrm{mg} \cdot \mathrm{mL}^{-1}$.

\subsubsection{Fourier-transform infrared spectroscopy (FT-IR)}

Fourier transform infrared spectroscopy (Perkin Elmer) equipped with attenuated total reflection (Golden Gate, Specac) was used to analyse the polymers after the extraction procedures and the surfactants after the solubilization tests. Commercial $\mathrm{P}(\mathrm{HB})$ (Sigma-Aldrich) was used as a reference to identify if any of the functional groups were present. A spectral range between $4000-500 \mathrm{~cm}^{-1}$ was used with 64 scans at a resolution of $4 \mathrm{~cm}^{-1}$. The raw signal was pre-processed by a baseline correction and then vector normalized, using the software Spectra. The equipment was located in a room with controlled temperature $\left(21 \pm 1{ }^{\circ} \mathrm{C}\right.$ ) and humidity (under $35 \pm 2 \%$ ) and background scans were performed before each analysis to prevent the interference of water and carbon dioxide.

\subsubsection{Differential scanning calorimetry (DSC)}

Differential Scanning Calorimetry (PerkinElmer, model Diamond DSC) was used to determine the thermal characteristics of the PHA extracted. Around $3 \mathrm{mg}$ of each PHA sample was placed in the DSC cell aluminium pan. The first heating ramp, with the aim to erase the thermal history, occurred at a rate of $5^{\circ} \mathrm{C} \cdot \mathrm{min}^{-1}$ from $-50{ }^{\circ} \mathrm{C}$ to $180^{\circ} \mathrm{C}$ (run I). Then, the temperature was held at $180^{\circ} \mathrm{C}$ for $1 \mathrm{~min}$ followed by a cooling ramp of 10 ${ }^{\circ} \mathrm{C}$. $\mathrm{min}^{-1}$ to $-50^{\circ} \mathrm{C}$. After $1 \mathrm{~min}$ at $-50^{\circ} \mathrm{C}$, the samples were reheated up to $180^{\circ} \mathrm{C}$ at a 5 ${ }^{\circ} \mathrm{C}$. $\mathrm{min}^{-1}$ rate (run II). An inert nitrogen atmosphere was used during the purge.

The melting temperature $\left(T_{m}\right)$ and the melting enthalpy $(\Delta H)$ were obtained considering the values from the thermogram obtained during the second heating ramp (run II). The crystallinity (Eq. 2) was calculated according to:

$$
\operatorname{Crystalinity~}(\%)=\frac{\Delta \mathrm{H}(\mathrm{J} / \mathrm{g})}{\Delta \mathrm{Ho}(\mathrm{J} / \mathrm{g}) \times \mathrm{w}} \times 100
$$

where $\Delta \mathrm{H}_{0}$ is melting enthalpy of the $100 \%$ crystalline PHB, which is assumed to be 146 J.g $\mathrm{g}^{-1}$ and $w$ is the weight fraction of PHB in the sample [34].

\subsubsection{Thermogravimetric analysis (TGA)}

Thermogravimetric analysis (Seteram, model Settsys Evolution 1750, TGA mode, $S$ sensor) was used to determine the thermal stability of the extracted PHA. Nitrogen was supplied at $50 \mathrm{~mL} \cdot \mathrm{min}^{-1}$. The furnace temperature was set from $0{ }^{\circ} \mathrm{C}$ to $800{ }^{\circ} \mathrm{C}$ with a heating rate of $10^{\circ} \mathrm{C} \cdot \mathrm{min}^{-1}$. 


\subsubsection{Economic analysis}

An economic analysis was performed to elucidate the impact of the material consumption on the production cost. Briefly, the total cost per batch (CoG/batch) considering the pre-treatment and DMC extraction and the cost per gram (CoG. $\mathrm{kg}^{-1}$ ) was calculated following Eq. 3 and for the pre-treatment step using surfactants, Eq. 4:

${\frac{\operatorname{CoG}}{\text { Batch }_{\text {Total }}}}^{=\text {Batch }_{\text {Surfactant }}}+\frac{\operatorname{CoG}}{\text { Batch }}_{D M C}$

$\frac{\operatorname{CoG}}{\text { Batch }}_{\text {Surfactant }}=$ Concentration $*$ Molar Weight $* \frac{\text { Biomass }}{\frac{S}{L} \text { ratio }} *$ Price

Moreover, for the extraction using DMC, Eq. 5 was applied:

$\frac{\operatorname{CoG}}{\text { Batch }}_{D M C}=\frac{\text { Biomass }}{\frac{S}{L} \text { Ratio }} *$ Price

To calculate CoG. $\mathrm{g}^{-1}$, both Eqs. 6 and 7 were applied:

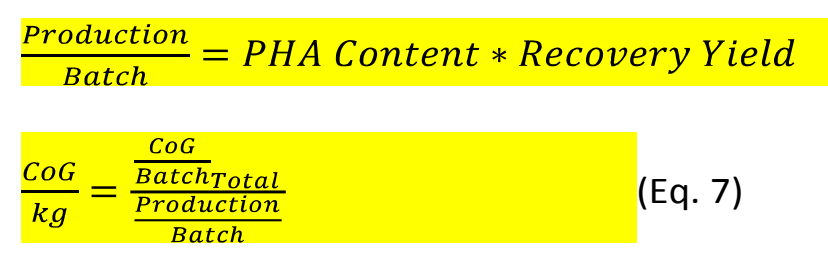

Using these equations, the CoG. $\mathrm{kg}^{-1}$ was calculated and the effect of different variables determined. This analysis considered large-scale production of 1,000 kg of biomass with a similar PHA content as the mixed microbial biomass used in this work and the 14 conditions ( 12 for surfactants and 2 as controls) here developed (Table 2 ). For this analysis, the only economic data needed were the prices in Euros obtained from the Alibaba website for the chemicals analysed, including the supplier, i.e. Tween $20-€ 0.95 . L^{-}$ ${ }^{1}$ (Qingdao Ocean Import And Export Co., Ltd.), Triton X-114 - €2.77.. ${ }^{-1}$ (Shaanxi Herben Bioengineering Co., Ltd.), Brij L4 - €0.82. L $^{-1}$ (Hebei Guanlang Biotechnology Co., Ltd.), DMC - €0.41. $\mathrm{L}^{-1}$ (Smileda Co., Ltd.), $\mathrm{CH}_{3} \mathrm{Cl}-€ 0.45 . \mathrm{L}^{-1}$ (Shandong S-Sailing Chemical Co., Ltd.).

Then, a sensitivity analysis (systematic variation of individual parameters) was performed to evaluate the impact of having variations in the price of the materials employed ( 50 or $200 \%$ from the current price), the recovery yield ( $\pm 20 \%$ of each of the values) and the PHA content in the biomass ( $\pm 25 \%$ to the current value of $50 \%)$. The best pre-treatment surfactant and condition were selected to perform an additional analysis. Finally, as an example of large-scale production, the CoG/batch and CoG. $\mathrm{g}^{-1}$ for a 1,000 $\mathrm{kg}$ of biomass processing were calculated, this along a subsequent sensitivity analysis.

\subsubsection{Carbon footprint determination}

The carbon footprint was determined for the three protocols to extract PHA as an indicator of environmental performance. It consists in the sum of greenhouse gas emissions (GHG), expressed as carbon dioxide equivalent $\left(\mathrm{CO}_{2} \mathrm{eq}\right)$, along the supply chain of the chemicals, water and electricity consumed (Table S1 of the Sup. Information). The quantities in Table 2 and the carbon footprint are expressed per $1 \mathrm{~kg}$ of PHA obtained, allowing for the comparison between the three protocols. Electricity consumption for 
each equipment was estimated based on the time of operation, nominal power and fraction of occupancy over total capacity. The adoption of the nominal power instead of the real power can lead to an overestimation of the electricity consumption and thus, it should be considered as the worst-case scenario. The carbon footprint for the supply chain of DMC, chloroform and electricity (considering the mix of energy sources of electricity consumed in Portugal) was sourced from the Ecoinvent 3.6 database [35], while for Tween 20, it was based on a manufacturer estimation [36]. For ultrapure water, the carbon footprint is associated with tap water production [37] and electricity consumed during ultra-purification [35]. The global warming potentials considered for each GHG are those recommended by the Intergovernmental Panel on Climate Change (IPCC) for a time horizon of 100 years [38].

\section{RESULTS AND DISCUSSION}

\subsection{Solubilisation tests}

PHAs solubility tests were performed for all surfactants. FT-IR of the liquid fraction after the solubilisation tests with PHA matched the spectra of the commercial surfactants, indicating that for all cases, the polymer was not soluble in the surfactants chosen (Figure S1 of the Sup. Information). Furthermore, none of the typical PHB bands were observed in the liquid fractions of the solubilisation tests.

\subsection{Tests with conventional methods}

The mixed microbial biomass used in this work had a PHAs content of $50 \%$ of cell dry weight. The polymer consisted of a copolymer of 3-hydroxybutyrate (3HB) and 3hydroxyvalerate $(3 \mathrm{HV}), \mathrm{P}(\mathrm{HB}-\mathrm{Co}-\mathrm{HV})$, with an $3 \mathrm{HV}$ molar content of $12 \%$. Part of this microbial biomass was used for the extraction of PHAs using chloroform $\left(\mathrm{CHCl}_{3}\right)$ and DMC, following the conditions proposed by Samorì et al. (2015), and being the main results presented in Table 2 . The PHA recovery yields, for both DMC and chloroform, $38.4 \%$ and $63.5 \%$, respectively, were lower than those previously obtained in literature, $49 \%$ [2] and $>90 \%[8,13]$, respectively. By mixing $0.1 \mathrm{~g}$ of lyophilized microbial biomass with DMC using the same $\mathrm{S} / \mathrm{L}$ ratio of $0.025 \mathrm{~g}_{\text {cells }} \cdot \mathrm{mL}_{\text {solvent }}{ }^{-1}$, the maximum recovery yield obtained was $38.4 \pm 0.8 \%$, which is a result $20 \%$ below the value reported by Samorì et al. (2015) for microbial biomass selected under different conditions and with a different substrate. This lower recovery could result from the use of different microbial cultures and substrates for PHAs production in Samorì et al. (2015) and in this work.

These results illustrate one of the problems of working with mixed microbial biomass. The different origin of the substrate and microbial inoculum used in each PHAs production process leads to different microbial compositions of biomass that can show different characteristics. While DMC seems to efficiently dissolve PHAs, it may not be ideal for cell disruption, limiting the solvent access to PHAs [14]. To overcome this problem, the introduction of a pre-treatment step was previously investigated using sodium hypochlorite ( $\mathrm{NaClO}$ ), that successfully helped in the disruption of the cells but high temperatures were required, $100^{\circ} \mathrm{C}$ for 1 hour [2]. Moreover, $\mathrm{NaClO}$ is far from being the best solution for a disrupting agent, due to its role in the formation of halogenated toxic by-products [39-41]. Finally, a reduction on the MW of the extracted polymer is usually observed, which can compromise future application of the polymer [1].

The results obtained with chloroform and DMC worked as controls for the subsequent assays, where the use of non-ionic surfactants as pre-treatment agent is proposed. 


\subsection{Pre-treatment with surfactants and ANOVA results}

In this work, a pre-treatment step using non-ionic surfactants was studied as a way of improving the DMC extraction and, consequently, the sustainability of the overall process. The pre-treatment consisted on the selective dissolution of the non-PHA cell mass (NPCM) with non-ionic surfactants. Table 2 shows the conditions applied and results obtained in these assays.

The results in Table 2 show that the highest S/L ratio, in general, allowed for better results with the three non-ionic surfactants at both concentrations tested. On the other hand, the surfactant concentrations tested did not seem to have a significant impact on the extraction procedure, which allowed choosing the lowest concentration, $100 \mathrm{mmol}$. $^{-}$ 1 , consequently decreasing the impact of the overall process. Preliminary assays showed that concentrations lower than $100 \mathrm{mmol}^{-\mathrm{L}^{-1}}$ resulted in lower yields (data not shown).

Moreover, it can be seen that for any condition adopted (surfactant concentration and S/L ratio), Triton ${ }^{\mathrm{TM}} \mathrm{X}-114$ resulted in the worst scores in terms of PHA recovery yield, while Tween 20 shows the best results, which correlates with the HLB data attributed to each surfactant (Triton X-114 with HLB = 12.3 [29], and Tween 20 with HLB = 16.7 [27]). In order to understand which of the conditions tested in the pre-treatment step allowed getting the best results (not statistically different), a one-way ANOVA was performed on the 12 tests. The results are expressed in Table 2 in terms of letters. The best results, marked in green in Table 2, were defined by the use of Tween ${ }^{\circledR} 20$ at 150 mmol.L $^{-1}$ independently of the $\mathrm{S} / \mathrm{L}$ ratio tested or at $100 \mathrm{mmol}^{-1} \mathrm{~L}^{-1}$ for the highest $\mathrm{S} / \mathrm{L}$ ratio tested, and $\mathrm{Brij}^{\circledast} \mathrm{L} 4$ at $150 \mathrm{mmol}^{-\mathrm{L}^{-1}}$ for the highest $\mathrm{S} / \mathrm{L}$ tested.

After the optimization of the different conditions and analysis of the results, Tween ${ }^{\circledR}$ 20 and $\mathrm{Brij}^{\circledR} \mathrm{L} 4$ were chosen as best digestive/disrupting agents of NPCM.

To further optimize the process, by reducing the amount of solvent needed in the process, a last assay was performed to evaluate the impact of the S/L ratio but in the second step, i.e. the extraction with DMC. In this context, instead of the 0.025 $\mathrm{g}_{\text {cells. }} \cdot \mathrm{mL}_{\text {solvent }}{ }^{-1}$ tested by Samorì et al. (2015), a S/L ratio of $0.075 \mathrm{~g}_{\text {cells }} \cdot \mathrm{mL}_{\text {solvent }}{ }^{-1}$ was applied. The recovery yield results obtained were notably lower (between 26 and $29 \%$ ) for the higher S/L ratio tested and even if compared with the use of sole DMC. This can be explained by the formation of a "gel-like" structure observed during this assay), which made impossible the separation of the DMC phase rich in PHA from the pre-treated microbial biomass. This may be justified by the precipitation of other cellular structures with DMC, like proteins, as previously observed [42]. Besides, it was well documented that disrupted biomasses produce amphiphilic molecules having colloidal properties [43]. For this reason, the $\mathrm{S} / \mathrm{L}$ ratio of $0.025 \mathrm{~g}_{\text {cells. }} \cdot \mathrm{mL}_{\text {solvent }}{ }^{-1}$ was used in further studies.

\subsection{Impact on molecular weight and polydispersity index}

The molecular weight ( $\mathrm{Mw}$ ) distribution is one of the main drivers controlling the enduse of PHAs, since it can limit several applications [1]. For this reason, the impact of the extraction procedure on the $\mathrm{Mw}$ of the polymer was studied. For the best conditions previously selected, the average $\mathrm{Mw}$ and polydispersity $(\mathrm{Mw} / \mathrm{Mn})$ of the PHAs obtained were determined (Table 3). The molecular weight of the samples ranged from 0.76 to $0.91 \mathrm{MDa}$, which is slightly lower than the initial value determined on the PHA extracted with $\mathrm{CHCl}_{3}, 1.0 \mathrm{MDa}$. The values are in range with the data reported in literature [44-47], but lower compared with what was reported by using sole DMC to extract PHA from a mixed culture, 1.3 MDa [2], a difference that could be due to the different biochemical characteristics of microbial biomass source. Still, the use of surfactants in the pretreatment step had a much lower impact on $\mathrm{Mw}$ that the currently proposed 
methods. Using $\mathrm{NaClO}$, Samorì et al. (2015) reported $\mathrm{Mw}$ decreases of 54 to 85\%, while in this work decreases ranged 9 to $24 \%$ [2].

The Mw reduction was more evident in the samples using $\operatorname{Tween}^{\circledR} 20$, which might indicate that this surfactant has a more significant impact in the polymer chain length, even though it led to higher extraction yields. Regardless of the lower molecular weights, the polydispersity indexes (PDI) of the samples were between 1.85 and 1.99, indicating narrow chain length distributions. The lower value of PDI for the assay with Brij L4 confirms the lower reduction on $\mathrm{Mw}$ observed. The values obtained were also in agreement with what was previously reported $[1,48]$. Considering all the results obtained, namely recovery yield, Mw and PDI, the work proceeded with Tween ${ }^{\circledR} 20$ and $\mathrm{Brij}^{\circledR} \mathrm{L} 4$ by adopting the best conditions representing tests 10 and 12 .

\subsection{Thermochemical characterization of PHA extracted after microbial biomass pre- treatment with Tween $^{\circledR} 20$ and Brij ${ }^{\circledR}$ L4}

The detailed thermo-chemical characterization of PHA after pre-treatment with Tween $^{\circledR} 20$ and Brij $^{\circledR} L 4$ for the best conditions represented by tests 10 and 12 was assessed by DSC, FTIR, TGA, and GC analysis. The results obtained are summarized in Table 4.

GC analysis was conducted on both samples. Results of the polymer extracted after pre-treatment with Tween ${ }^{\circledR} 20$ indicated a copolymer of P(HB-co-HV) with an HV content of $9 \%$ and a purity of $93.9 \%$ (g PHA/100 g total solids). Although a similar proportion of $\mathrm{HB} / \mathrm{HV}$ was determined for the PHA extracted after cell disruption with Brij ${ }^{\circledR}$ L4, the purity was much lower, $56.8 \%$ (g PHA/100 g total solids), which may be attributed to the presence of contaminations, possibly the surfactant itself, or other compounds released during the pre-treatment step.

DSC is an extremely useful tool for the characterization of PHAs thermal properties [1]. In this work, this technique was used to determine the melting temperature $\left(T_{m}\right)$, enthalpy $\left(\Delta \mathrm{H}_{\mathrm{m}}\right)$, and the glass transition temperature $\left(T_{\mathrm{g}}\right)$ of the polymers extracted with Brij ${ }^{\circledR} L 4$ and Tween ${ }^{\circledR} 20$. The crystallinity was determined from the values of $\Delta H_{m}$. Both samples showed similar values of $\mathrm{T}_{\mathrm{m}}$ and $\mathrm{T}_{\mathrm{g}}$ and corresponded to the values reported for copolymers with similar HV content $[44,46,49,50]$. The major differences observed between the samples were in the melting enthalpy, and, consequentially, in the crystallinity. While the values of crystallinity obtained for the sample extracted with Brij ${ }^{\circledR}$ L4 were more consistent with what was previously reported for $\mathrm{P}(3 \mathrm{HB}-\mathrm{co}-3 \mathrm{HV})$ with $9 \%$ $\mathrm{HV}$ content [49], a wide range of crystallinity values has been reported [1,51-53]. Besides, as reviewed by Laycock et al. (2013), DSC is not the ideal technique for the measurements of crystallinity, especially for copolymers [1].

FT-IR has been often used as a method of "real-time" detection and characterisation of PHAs, since it requires a small sample size, minimal sample preparation, and it is of rapid analysis, without solvents need [52]. Figure 1 compares the spectra of the PHAs extracted using both surfactants with PHAs extracted with $\mathrm{CHCl}_{3}$ and a $\mathrm{PHB}$ commercial standard. The similarity between all spectra is evident and consistent with the previously reported PHA spectra [54]. As seen in Figure 1A, typical PHAs peaks are evident in both samples, with the peak corresponding to the ester carbonyl $(C=O)$ stretching in the 1740 $1700 \mathrm{~cm}^{-1}$ region and the $-\mathrm{CH}_{3}$ and $-\mathrm{CH}_{2}$ - stretching at $3000-2800 \mathrm{~cm}^{-1}$. Regarding PHAs composition, $\mathrm{HV}$ content is thought not to cause significant variations in the spectra. However, because crystallinity has a tendency to decrease with the increase of the HV content, subtle shifts in some of the bands related to crystallinity have been observed, especially in the $1740-1700 \mathrm{~cm}^{-1}$ region [55]. Kansiz et al. (2007) studied the FTIR spectra of PHA copolymers with $14 \%$ of $\mathrm{HV}$ and its correlation with polymer crystallisation. These authors observed major changes in the carbonyl band at around $1730 \mathrm{~cm}^{-1}$. In this case, 
two bands were observed: a broader band at $1740 \mathrm{~cm}^{-1}$ and a stronger and sharper band at $1720 \mathrm{~cm}^{-1}$ corresponding to the amorphous and crystalline phases, respectively. Figure $1 \mathrm{~B}$ represents this specific region where the presence of the reported bands is more evident in the extracted samples than in the homopolymer. Also, both samples extracted with $\mathrm{CHCl}_{3}$ and Tween ${ }^{\circledR} 20$ exhibited lower peaks than the PHB standard, this being consistent with the presence of the HV monomer. Finally, a peak in the $2290-2390 \mathrm{~cm}^{-1}$ region of the sample extracted with $\mathrm{Brij}^{\circledR} \mathrm{L} 4$ can be observed in Figure $1 \mathrm{C}$, which could confirm the lower purity of the sample determined by GC.

Both samples were also submitted to TGA analysis to evaluate their thermal stability (Figure 2).

TGA analysis presented a major drop in mass at temperatures between $200-330{ }^{\circ} \mathrm{C}$, corresponding to the thermal decomposition of $\mathrm{PHA}$, regardless of the surfactant used in the pre-treatment (Figure 2A). For the sample extracted with Tween ${ }^{\circledR} 20$, there was an almost complete loss of mass, until $270{ }^{\circ} \mathrm{C}$, with only residual weight loss further observed until $400^{\circ} \mathrm{C}$. These results indicate the higher purity of the sample, around $90 \%$, a value determined by measuring the main slope of the TGA curve [30]. Extraction of PHA after cell digestion with $B \mathrm{Brij}^{\circledR} \mathrm{L} 4$ resulted in a polymer with a higher content of impurities, with a mass loss between $250-400{ }^{\circ} \mathrm{C}$ that can be observed in the TGA curve, confirming the result from GC. This result is usually associated with the presence of organic compounds [10].

Figure $2 \mathrm{~B}$ represents the variation of the rate of decomposition with increasing temperature (in terms of the conversion derivative curve of the TGA) of both samples. This analysis allows for the determination of the temperature of maximum PHA decomposition $\left(T_{d}\right)$ with a good degree of precision [56]. The samples had similar $T_{d}$ with $242.62^{\circ} \mathrm{C}$ and $255.38{ }^{\circ} \mathrm{C}$ for $\mathrm{Brij}^{\circledR} \mathrm{L} 4$ and $\operatorname{Tween}^{\circledR} 20$, respectively. The results were in range with previously values reported for $\mathrm{P}(3 \mathrm{HB}-\mathrm{co}-3 \mathrm{HV})$ produced by mixed microbial biomass [1]. Regardless of the slightly lower values of $T_{d}$ obtained in this work when compared with literature $[10,56]$, the phenomenon should be expected considering the lower HV content [56].

\subsection{Economic and environmental analysis of the proposed method}

This paper proposes a two-step process using a pre-treatment of the mixed microbial biomass to extract PHA. From the two non-ionic surfactants that led to the best recovery yields, the choice was Tween 20 followed by the extraction of PHA with DMC, to successfully developed the PHA recovery. This non-ionic surfactant was efficiently used to induce the cell disruption in a concentration of $150 \mathrm{mM}$ and a $\mathrm{S} / \mathrm{L}$ ratio of 0.0625 $\mathrm{g}_{\text {cells. }} \mathrm{mL}_{\text {solvent }}{ }^{-1}$. The optimization of the first step allowed thus the easiest recovery of PHA with high recovery yields (53 $\pm 2 \%$ ) and purity (93.9\%), maintaining the high molecular weight of the biopolymer (around $0.80 \mathrm{kDa}$ ), when compared with the use of DMC alone for the same consortia (experimental results also performed in this work). However, and foreseeing the future industrial implementation, the recycling and reuse of the main solvents are essential steps. In this work, these steps were contemplated. The surfactant may be directly reused, since it is not dissolving the PHA, as it only acts in cell disruption. The DMC used in the second step was completely separated from the biopolymer by evaporation as also defined in the final process depicted in Figure 3.

In order to confirm the feasibility of the proposed process an economic evaluation and a carbon footprint analysis were performed.

\subsubsection{Economic analysis}

To understand the impact of the addition of an extra pre-treatment step in the final cost of the extraction process, an economic analysis was conducted, where the CoG per 
kilogram of PHA was evaluated for each condition tested. The calculation of the CoG.kg${ }^{1}$ for the 14 assays shows that the least expensive option is the application of $\mathrm{CH}_{3} \mathrm{Cl}$ for PHA extraction, with a $€ 57.7$ per kilogram when processing $1,000 \mathrm{~kg}$ of biomass (Figure $4 \mathrm{~A})$. However, and as mentioned before, the use of chloroform is the least green alternative [2]. All the pre-treatment conditions resulted in a lower production cost, between $€ 68.6$ per kilogram, for assay 12 , and $€ 123.6$ per kilogram, for assay 2 , with the use of sole DMC resulting in one of the highest costs, $€ 85.4$ per kilogram (Figure 4A). These results are highly associated with the recovery yields obtained; the use of only DMC resulted in a recovery yield of $38.4 \%$, while assay 2 showed a recovery of $34 \%$.

A sensitivity analysis performed on the materials costs, recovery yield and PHA content (Figure 5) shows that for the majority of the assays, the most critical parameter is the materials cost. As recovery decreases (assays 2 and 13), it became more important, but if it maintains a level above $40 \%$ (as with the rest of the conditions tested), it is criticality decreased. Moreover, the amount of PHA in the biomass also plays a major role in dictating the potential production costs.

The results from the deterministic and sensitivity analyses allowed to prove that the inclusion of a pre-treatment step was indeed the best option, especially considering assay 10 (Tween 20, $150 \mathrm{mM}, \mathrm{S} / \mathrm{L}$ ratio of 0.0625 ), which corresponds to the process proposed, since it showed the best operational results with a recovery of $53 \%$ and a purity of $93 \%$ and one of the lowest costs, $€ 71.5$ per kilogram. In order to decrease the extraction costs, the optimization should also include the reutilization of DMC or its substitution for a cheaper solvent with similar characteristics, since for assay 10, DMC corresponded to $86.5 \%$ of the costs. As mentioned previously, in addition to the direct reuse of Tween 20 in new pre-treatment cycles, the recycling of the solvent will be also relevant to decrease even more the amounts used, and consequently the overall costs.

In this work, the impact of the recovery yield was evaluated aiming to understand its impact on the final costs. However, in practice, an improvement on the yield would be a result of some modifications on the experimental conditions (e.g. S/L ratio). Another aspect that needs optimization is the PHA content of the mixed microbial biomass, since a higher amount produced would result in a higher amount extracted. Consequently, an improvement on the production and recovery yields would result in a decrease of the CoG. $\mathrm{kg}^{-1}$, which will decrease, as more product is being formed. Still, the values expected would be higher considering that this calculation was only based on the cost of the chemicals not contemplating the associated costs of equipment and energy consumption, just to mention a few.

\subsubsection{Carbon footprint analysis}

To ensure that the pretreatment step added to the process does not have a negative environmental impact on the process, a carbon footprint analysis was conducted. The results showed that the protocol with the lowest carbon footprint was the protocol proposed in this study ( $213 \mathrm{~kg} \mathrm{CO}_{2}$ eq. $\left.\mathrm{kg}^{-1} \mathrm{PHA}\right)$, followed by the alternative $\mathrm{DMC}$ protocol proposed by Samori et al. (2015) (228 $\mathrm{kg} \mathrm{CO}_{2}$ eq. $\mathrm{kg}^{-1} \mathrm{PHA}$ ) and the conventional protocol with $\mathrm{CH}_{3} \mathrm{Cl}$ (372 kg CO 2 eq. $\mathrm{kg}^{-1} \mathrm{PHA}$ ) (Figure 6). In comparison with the alternative DMC protocol, the proposed process has a lower carbon footprint because the decrease of the amount of DMC consumed leads to a reduction of the carbon footprint that is higher than the increase associated with the additional consumption of Tween 20 and water, and the increased consumption of electricity. The largest contribution to the carbon footprint of these two protocols comes from the DMC production (Figure 6). The conventional protocol has a carbon footprint $74 \%$ higher than the protocol proposed in this work, being dominated mainly by the chloroform production (Figure 6). 
Summing up, this work provided an alternative process to extract and purify PHA in a more sustainable way, which means, with high efficiency and more environmental and economically viable.

\section{CONCLUSIONS}

Since the lack of a cost-effective production process still hinders the wider implementation of PHA in the market, the development of new processes to efficiently extract PHA is urgent. A sustainable process may help to decrease the production costs, while maintaining the environmentally friendly nature of the technology, is essential. In this work, the addition of a pre-treatment based on non-ionic surfactants to extract PHA from mixed microbial biomass selected on fermented agro-industrial wastes was investigated. It allowed to increase the PHA recovery efficiency by $50 \%$ during the DMC extraction step from $38.4 \pm 0.8 \%$ to $53 \pm 2 \%$ [2]. Furthermore, the best results obtained were very close $(53 \pm 2 \%)$ to the yield obtained after using chloroform to extract PHAs (63\%). Additionally, the economic evaluation determined that this pre-treatment step is less expensive than the use of only DMC, with the condition selected being the least expensive option, and the carbon footprint analysis determined it to be the more environmentally friendly. The results showed that the addition of a pre-treatment step focused on biomass disruption not only increases the extraction yield but also creates a more robust process, that can be applied to different types of microbial biomass. The use of non-ionic surfactants also has a lower impact on $\mathrm{Mw}(<25 \%)$ compared to the current pre-treatment alternatives, whose harsh chemicals and operational conditions decrease the polymer molecular weight up to $85 \%$. Finally, the several analytical techniques used showed that the developed process resulted in PHAs of high purity, without the involvement of an undoubtedly toxic solvent, showing its contribution to reduce costs and environmental impact of PHAs production, as proved in this work by the economic evaluation and determination of carbon footprint.

\section{Acknowledgments}

This work was developed within the scope of the project CICECO-Aveiro Institute of Materials (UIDB/50011/2020 \& UIDP/50011/2020), Associate Laboratory for Green Chemistry - LAQV (UIDB/50006/2020), and CESAM (UIDB/50017/2020 \& UIDP/50017/2020) financed by national funds through the FCT/MCTES and when appropriate co-financed by FEDER under the PT2020 Partnership Agreement. This work was also financed by Regione Lombardia, Italian Government and European CommunityProgramma Operativo Regionale 2014-2020, Obiettivo "Investimenti in Favore della Crescita e dell'Occupazione Asse Prioritario I - Rafforzare la Ricerca, lo Sviluppo e I'Innovazione. Azione I.1.b.1.3-Sostegno alle attività collaborative di R\&S per lo sviluppo di nuove tecnologie sostenibili, di nuovi prodotti e Servizi. Project ID 141082: Renewable RAw materials valorization for INnovative BiOplastic production from urban Waste (RAINBOW). The authors are grateful for the financial support of the Portuguese Foundation for Science and Technology (FCT) for the contract SFRH/BD/130003/2017 of J. Pereira, SFRH/BD/122220/2016 of M. Martins, IF/01054/2014/CP1224/CT0005 of Paulo C. Lemos, and CEECIND/02174/2017 of Ana Dias. Mario A. Torres-Acosta gratefully acknowledges the support of the CONACYT grant No. 485025. 


\section{References}

[1] B. Laycock, P. Halley, S. Pratt, A. Werker, P. Lant, The chemomechanical properties of microbial polyhydroxyalkanoates, Prog. Polym. Sci. 38 (2013) 536-583.

https://doi.org/10.1016/j.progpolymsci.2013.06.008.

[2] C. Samorì, F. Abbondanzi, P. Galletti, L. Giorgini, L. Mazzocchetti, C. Torri, E. Tagliavini, Extraction of polyhydroxyalkanoates from mixed microbial cultures: Impact on polymer quality and recovery, Bioresour. Technol. 189 (2015) 195-202. https://doi.org/10.1016/j.biortech.2015.03.062.

[3] Z. Sun, J.A. Ramsay, M. Guay, B.A. Ramsay, Fermentation process development for the production of medium-chain-length poly-3-hydroxyalkanoates, Appl. Microbiol. Biotechnol. 75 (2007) 475-485. https://doi.org/10.1007/s00253-007-0857-4.

[4] Z.U. Salmiati, M.R. Salim, G. Olsson, Recovery of Polyhydroxyalkanoates (PHAs) from Mixed Microbial Cultures by Simple Digestion and Saponification, in: Proc. 3rd Int. Water Assoc. (IWA)-ASPIRE Conf. Exhib., 2009: pp. 8-15.

[5] M. Patel, D.J. Gapes, R.H. Newman, P.H. Dare, Physico-chemical properties of polyhydroxyalkanoate produced by mixed-culture nitrogen-fixing bacteria, Appl. Microb. Cell Physiol. 82 (2009) 545-555. https://doi.org/10.1007/s00253-008-1836-0.

[6] L.S. Serafim, D. Queirós, S. Rossetti, P.C. Lemos, Biopolymer Production by Mixed Microbial Cultures: Integrating Remediation with Valorization, in: Recent Adv. Biotechnol., Bentham Books, 2016: pp. 26-264. https://doi.org/10.2174/9781681083254116010007.

[7] M.R. Kosseva, E. Rusbandi, Trends in the biomanufacture of polyhydroxyalkanoates with focus on downstream processing, Int. J. Biol. Macromol. 107 (2018) 762-778. https://doi.org/10.1016/j.ijbiomac.2017.09.054.

[8] G. Mannina, D. Presti, G. Montiel-jarillo, J. Carrera, M.E. Suárez-ojeda, Recovery of polyhydroxyalkanoates (PHAs) from wastewater : A review, Bioresour. Technol. 297 (2020) 122478. https://doi.org/10.1016/j.biortech.2019.122478.

[9] M. Villano, F. Valentino, A. Barbetta, L. Martino, M. Scandola, M. Majone, Polyhydroxyalkanoates production with mixed microbial cultures: from culture selection to polymer recovery in a high-rate continuous process, N. Biotechnol. 31 (2014) 289-296. https://doi.org/10.1016/j.nbt.2013.08.001.

[10] A. Burniol-Figols, I. V. Skiadas, A.E. Daugaard, H.N. Gavala, Polyhydroxyalkanoate (PHA) purification through dilute aqueous ammonia digestion at elevated temperatures, Chem. Technol. Biotechnol. (2020). https://doi.org/10.1002/jctb.6345.

[11] G.-Y. Tan, C.-L. Chen, L. Li, L. Ge, L. Wang, I. Razaad, Y. Li, L. Zhao, Y. Mo, J.-Y. Wang, Start a Research on Biopolymer Polyhydroxyalkanoate (PHA): A Review, Polymers (Basel). 6 (2014) 706-754. https://doi.org/10.3390/polym6030706.

[12] M.H. Madkour, D. Heinrich, M.A. Alghamdi, I.I. Shabbaj, A. Steinbüchel, PHA recovery from biomass., Biomacromolecules. 14 (2013) 2963-72. https://doi.org/10.1021/bm4010244.

[13] C. Kourmentza, J. Plácido, N. Venetsaneas, A. Burniol-Figols, C. Varrone, H.N. Gavala, M.A.M. Reis, Recent Advances and Challenges towards Sustainable Polyhydroxyalkanoate (PHA) Production, Bioengineering. 4 (2017) 55. https://doi.org/10.3390/bioengineering4020055.

[14] M. Koller, H. Niebelschütz, G. Braunegg, Strategies for recovery and purification of poly[(R)-3hydroxyalkanoates] (PHA) biopolyesters from surrounding biomass, Eng. Life Sci. 13 (2013) 549-562. https://doi.org/10.1002/elsc.201300021.

[15] J. Choi, S.Y. Lee, Efficient and Economical Recovery of Poly (3-Hydroxybutyrate) from Recombinant Escherichia coli by Simple Digestion with Chemicals, Biotechnol. Bioeng. 62 (1999) 546-553.

[16] S. Pyo, J. Hoon, T. Chang, Dimethyl carbonate as a green chemical, Curr. Opin. Green Sustain. Chem. 5 (2017) 61-66. https://doi.org/10.1016/j.cogsc.2017.03.012.

[17] Y. Jiang, G. Mikova, R. Kleerebezem, L.A.M. Van Der Wielen, M.C. Cuellar, Feasibility study of an alkalinebased chemical treatment for the purification of polyhydroxybutyrate produced by a mixed enriched culture, AMB Express. 5 (2015) 1-13. https://doi.org/10.1186/s13568-015-0096-5.

[18] C. Samorì, M. Basaglia, S. Casella, L. Favaro, P. Galletti, L. Giorgini, D. Marchi, L. Mazzocchetti, C. Torri, E. Tagliavini, Dimethyl carbonate and switchable anionic surfactants: two effective tools for the extraction of polyhydroxyalkanoates from microbial biomass, Green Chem. 17 (2015) 1047-1056. https://doi.org/10.1039/c4gc01821d.

[19] F.A. Vieira, R.J.R. Guilherme, M.C. Neves, H. Abreu, E.R.O. Rodrigues, M. Maraschin, J.A.P. Coutinho, S.P.M. Ventura, Single-step extraction of carotenoids from brown macroalgae using non-ionic surfactants, Sep. Purif. Technol. 172 (2017) 268-276. https://doi.org/10.1016/j.seppur.2016.07.052.

[20] M. Alhattab, A. Kermanshahi-Pour, M.S. Brooks, Microalgae disruption techniques for product recovery: influence of cell wall composition, J. Appl. Phycol. 1 (2019) 61-88.

[21] E. Owen, J. Clifford, a Marson, The effects of surfactants on cell aggregation., J. Cell Sci. 32 (1978) 363-376.

[22] M.F. Zaki, S.M. Tawfik, Synthesis, Surface Properties and Antimicrobial Activity of Some Germanium Nonionic Surfactants, J. Oleo Sci. 931 (2014) 921-931. 
[23] S. Murugesan, R. lyyasamy, Nonionic surfactants induced cloud point extraction of Polyhydroxyalkanoate from Cupriavidus necator, Sep. Sci. Technol. 52 (2017) 1929-1937.

https://doi.org/10.1080/01496395.2017.1307227.

[24] S. Murugesan, R. Iyyaswami, Low frequency sonic waves assisted cloud point extraction of polyhydroxyalkanoate from Cupriavidus necator, J. Chromatogr. B. 1060 (2017) 207-214. https://doi.org/10.1016/j.jchromb.2017.06.009.

[25] F.A. Vieira, S.P.M. Ventura, Efficient extraction of carotenoids from Sargassum muticum using aqueous solutions of Tween 20, Mar. Drugs. 17 (2019) 1-10.

[26] B. Colombo, M.V. Calvo, T.P. Sciarria, B. Scaglia, S.S. Kizito, G.D. Imporzano, F. Adani, Biohydrogen and polyhydroxyalkanoates (PHA) as products of a two-steps bioprocess from deproteinized dairy wastes, Waste Manag. 95 (2019) 22-31. https://doi.org/10.1016/j.wasman.2019.05.052.

[27] Eshelman School of Pharmacy, Commonly Used Emulsifiers And Their HLB Values, (2020). https://pharmlabs.unc.edu/labs/emulsions/hlb.htm.

[28] Croda Crop Care, Brij ${ }^{T M}$ L4 - Product Description, (2020). https://www.crodacropcare.com/en-gb/productsand-applications/product-finder/product/5/Brij_1_L4.

[29] Dow Chemical Company, TRITONTM X-114 Surfactant - Chemical Description, (2020). https://nshosting.dow.com/doc-archive/business/pcm/triton/triton_x-114/tds/triton_x-114.pdf.

[30] S.K. Hahn, Y.K. Chang, A thermogravimetric analysis for poly(3-hydroxybutyrate) quantification, Biotechnol. Tech. 9 (1995) 873-878.

[31] A.F. Duque, C.S.S. Oliveira, I.T.D. Carmo, A.R. Gouveia, F. Pardelha, A.M. Ramos, M. a M. Reis, Response of a three-stage process for PHA production by mixed microbial cultures to feedstock shift: Impact on polymer composition, N. Biotechnol. 31 (2014) 276-288. https://doi.org/10.1016/j.nbt.2013.10.010.

[32] M.V. Calvo, B. Colombo, L. Corno, G. Eisele, C. Cosentino, G. Papa, B. Scaglia, R. Pilu, B. Simmons, F. Adani, Bioconversion of Giant Cane for Integrated Production of Biohydrogen, Carboxylic Acids, and Polyhydroxyalkanoates (PHAs) in a Multistage Biore fi nery Approach, ACS Sustain. Chem. Eng. 6 (2018) 15361-15373. https://doi.org/10.1021/acssuschemeng.8b03794.

[33] R. Moita, P.C. Lemos, Biopolymers production from mixed cultures and pyrolysis by-products., J. Biotechnol. 157 (2012) 578-83. https://doi.org/10.1016/j.jbiotec.2011.09.021.

[34] P.A. Barker, P.J. Barham, Effect of crystallization temperature cocrystallization of hydroxybutyrate/hydroxyvalerate copolymers, Polymer (Guildf). 38 (1997) 913-919.

[35] G. Wernet, C. Bauer, B. Steubing, J. Reinhard, E. Moreno-ruiz, B. Weidema, The ecoinvent database version 3 (part I): overview and methodology, Int. J. Life Cycle Assess. 21.3 (2016) 1218-1230. https://doi.org/10.1007/s11367-016-1087-8.

[36] Croda, ECO non-ionic surfactants, (n.d.). http://www.crodacropcare.com/en-gb/discoveryzone/sustainability-at-croda/eco-non-ionic-surfactant.

[37] D. Lemos, A. Dias, X. Gabarrell, L. Arroja, Environmental assessment of an urban water system, J. Clean. Prod. 54 (2013) 157-165. https://doi.org/10.1016/j.jclepro.2013.04.029.

[38] G. Myhre, D. Shindell, F. Bréon, W. Collins, J. Fuglestvedt, J. Huang, D. Koch, J. Lamarque, D. Lee, B. Mendoza, T. Nakajima, A. Robock, G. Stephens, T. Takemura, H. Zhang, Contribution of Working Group I to the Fifth Assessement Report of the Intergovernmental Panel on Climate Change, in: Clim. Chang. 2013 Phys. Sci. Basics, Cambridge University Press, Cambridge, 2013: pp. 659-740.

[39] I. Johnson, J.A. Pickup, D. van Wijk, A perspective on the environmental risk of halogenated by-products from uses of hypochlorite using a whole effluent toxicity based approach, Environ. Toxicol. Chem. 25 (2006) 1171-1177.

[40] M. Odabasi, Halogenated Volatile Organic Compounds from the Use of Chlorine-Bleach-Containing Household Products, Environ. Sci. Technol. 42 (2008) 1445-1451.

[41] Z. Wang, J. Ding, P. Xie, Y. Chen, Y. Wan, S. Wang, Formation of halogenated by-products during chemical cleaning of humic acid-fouled UF membrane by sodium hypochlorite solution, Chem. Eng. J. 332 (2018) 7684. https://doi.org/10.1016/j.cej.2017.09.053.

[42] D.C. Panadare, V.K. Rathod, Extraction of peroxidase from bitter gourd (Momordica charantia) by Three Phase Partitioning with dimethyl carbonate (DMC) as organic phase, Process Biochem. 61 (2017). https://doi.org/10.1016/j.procbio.2017.06.028.

[43] G. Quadri, X. Chen, J.W. Jawitz, F. Tambone, P. Genevini, F. Faoro, F. Adani, Biobased Surfactant-Like Molecules from Organic Wastes: The Effect of Waste Composition and Composting Process on Surfactant Properties and on the Ability to Solubilize Tetrachloroethene (PCE), Environ. Sci. Technol. 42 (2008) 26182623. https://doi.org/10.1021/es702144t.

[44] F. Morgan-Sagastume, A. Karlsson, P. Johansson, S. Pratt, N. Boon, P. Lant, A. Werker, A. Ab, Production of polyhydroxyalkanoates in open, mixed cultures from a waste sludge stream containing high levels of soluble organics, nitrogen and phosphorus, Water Res. 44 (2010) 5196-5211. https://doi.org/10.1016/j.watres.2010.06.043.

[45] M.G.E. Albuquerque, M. Eiroa, C. Torres, B.R. Nunes, M.A.M. Reis, Strategies for the development of a side stream process for polyhydroxyalkanoate (PHA) production from sugar cane molasses, J. Biotechnol. 130 (2007) 411-421. https://doi.org/10.1016/j.jbiotec.2007.05.011. 
[46] M.G.E. Albuquerque, V. Martino, E. Pollet, L. Avérous, M.A.M. Reis, Mixed culture polyhydroxyalkanoate (PHA) production from volatile fatty acid (VFA)-rich streams: Effect of substrate composition and feeding regime on PHA productivity, composition and properties, J. Biotechnol. 151 (2011) 66-76. https://doi.org/10.1016/j.jbiotec.2010.10.070.

[47] S. Bengtsson, A.R. Pisco, M.A.M. Reis, P.C. Lemos, Production of polyhydroxyalkanoates from fermented sugar cane molasses by a mixed culture enriched in glycogen accumulating organisms, J. Biotechnol. 145 (2010) 253-263. https://doi.org/10.1016/j.jbiotec.2009.11.016.

[48] P.C. Lemos, C. Levantesi, L.S. Serafim, S. Rossetti, M.A.M. Reis, Microbial characterisation of polyhydroxyalkanoates storing populations selected under different operating conditions using a cellsorting RT-PCR approach, Appl. Microbiol. Biotechnol. 78 (2008) 351-360. https://doi.org/10.1007/s00253007-1301-5.

[49] L.S. Serafim, P.C. Lemos, C. Torres, M.A.M. Reis, A.M. Ramos, The influence of process parameters on the characteristics of polyhydroxyalkanoates produced by mixed cultures, Macromol. Biosci. 8 (2008) 355-366. https://doi.org/10.1002/mabi.200700200.

[50] L. Hilliou, D. Machado, C.S.S. Oliveira, A.R. Gouveia, M.A.M. Reis, S. Campanari, M. Villano, M. Majone, Impact of fermentation residues on the thermal, structural, and rheological properties of polyhydroxy(butyrate-co-valerate) produced from cheese whey and olive oil mill wastewater, J. Appl. Polym. Sci. 133 (2016) 42818. https://doi.org/10.1002/app.42971.

[51] M.A.M. Reis, L.S. Serafim, P.C. Lemos, A.M. Ramos, F.R. Aguiar, M.C.M. Van Loosdrecht, Production of polyhydroxyalkanoates by mixed microbial cultures, Bioprocess Biosyst. Eng. 25 (2003) 377-385. https://doi.org/10.1007/s00449-003-0322-4.

[52] M. Kansiz, A. Domínguez-vidal, D. Mcnaughton, B. Lendl, Fourier-transform infrared (FTIR) spectroscopy for monitoring and determining the degree of crystallisation of polyhydroxyalkanoates (PHAs), Anal Bioanal Chem. 388 (2007) 1207-1213. https://doi.org/10.1007/s00216-007-1337-5.

[53] B. Laycock, M.V. Arcos-Hernandez, A. Langford, J. Buchanan, P.J. Halley, A. Werker, P.A. Lant, S. Pratt, Thermal Properties and Crystallization Behavior of Fractionated Blocky and Random Polyhydroxyalkanoate Copolymers from Mixed Microbial Cultures, J. Appl. Polym. Sci. 131 (2014) 40836. https://doi.org/10.1002/app.40836.

[54] T.G. Volova, N.O. Zhila, E.I. Shishatskaya, P. V Mironov, A.G. Sukovatyi, A.J. Sinskey, The Physicochemical Properties of Polyhydroxyalkanoates with Different Chemical Structures, 55 (2013) 427-437. https://doi.org/10.1134/S0965545X13070080.

[55] M. V Arcos-Hernandez, N. Gurieff, S. Pratt, P. Magnusson, A. Werker, A. Vargas, P. Lant, Rapid quantification of intracellular PHA using infrared spectroscopy: An application in mixed cultures, J. Biotechnol. 150 (2010) 372-379. https://doi.org/10.1016/j.jbiotec.2010.09.939.

[56] F. Carrasco, D. Dionisi, A. Martinelli, M. Majone, Thermal Stability of Polyhydroxyalkanoates, J. Appl. Polym. Sci. 100 (2006). https://doi.org/10.1002/app.23586. 


\section{FIGURE CAPTIONS}

Figure 1. A: FTIR spectra of the PHA extracted compared to a commercial standard (STD $\mathrm{P}(3 \mathrm{HB})$ ); $\mathrm{B}$ : Close-up of the FTIR spectra in the $1740-1700 \mathrm{~cm}^{-1}$ region ( $\mathrm{C}=\mathrm{O}$ stretching); $\mathrm{C}$ : Close-up of the FTIR spectra in the $2290-2390 \mathrm{~cm}^{-1}$ region.

Figure 2. A: TGA curve of the polymers extracted after biomass pre-treatment with $\mathrm{Brij}^{\circledR}$ L4 and Tween ${ }^{\circledast} 20$; B: Derivate of the weight (\%) vs. temperature (으) of samples and the corresponding $T_{d}$ values.

Figure 3. Schematic representation of the several steps of the final process.

Figure 4. Results for the economic analysis considering 1,000 kg of biomass. A: Results for the CoG. $\mathrm{kg}^{-1}$ for the 14 assays presented in Table; B: Results for the sensitivity analysis (difference between highest and lowest calculated CoG. $\mathrm{kg}^{-1}$ ) for the materials costs variation ( 50 or $200 \%$ of the current price), recovery yield $( \pm 20 \%)$ and PHA content $( \pm 25 \%)$.

Figure 5. Sensitivity analysis for extraction including pre-treatment with Tween $20, \mathrm{~S} / \mathrm{L}$ ratio of 0.0625 and $150 \mathrm{mM}$ for the materials cost variation (50 or $200 \%$ of the current price), recovery yield $( \pm 20 \%)$ and PHA content $( \pm 25 \%)$.

Figure 6. The carbon footprint for the proposed protocol (meaning final process depicted in Figure 3), for the protocol using only DMC and for the conventional process using chloroform. 

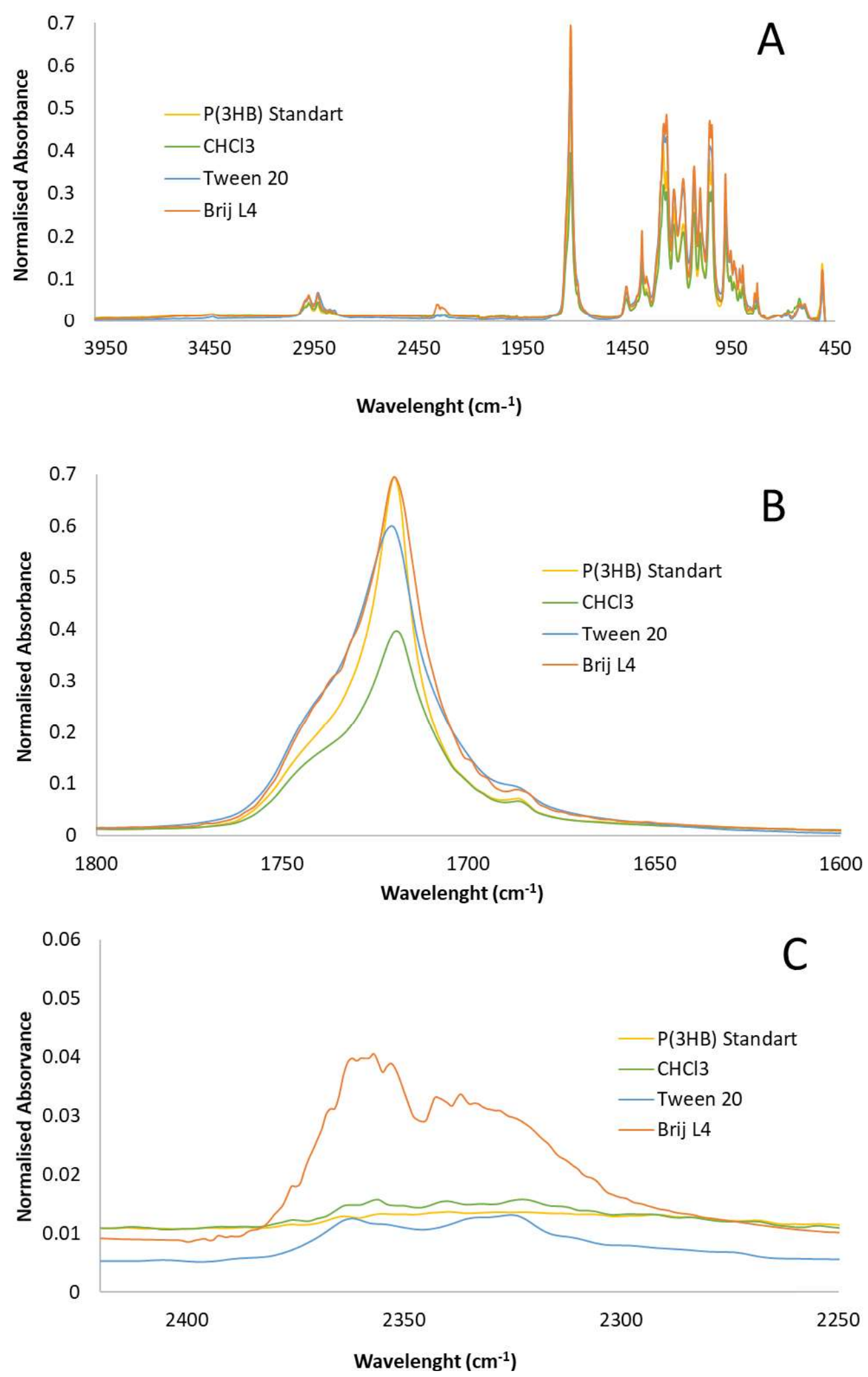

Figure 1. A: FTIR spectra of the PHA extracted compared to a commercial standard (STD $\mathrm{P}(3 \mathrm{HB})$ ); $\mathrm{B}$ : Close-up of the FTIR spectra in the $1740-1700 \mathrm{~cm}^{-1}$ region ( $\mathrm{C}=\mathrm{O}$ stretching); $\mathrm{C}$ : Close-up of the FTIR spectra in the $2290-2390 \mathrm{~cm}^{-1}$ region. 


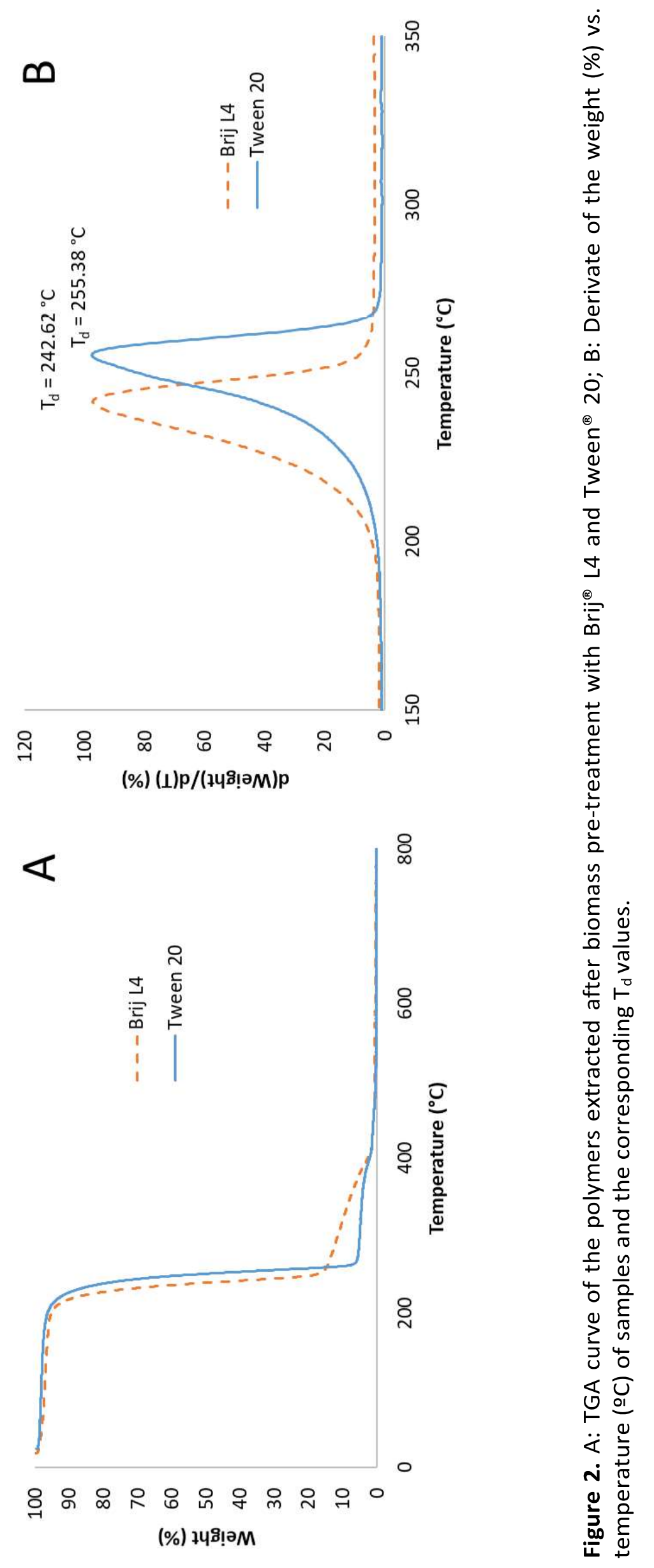




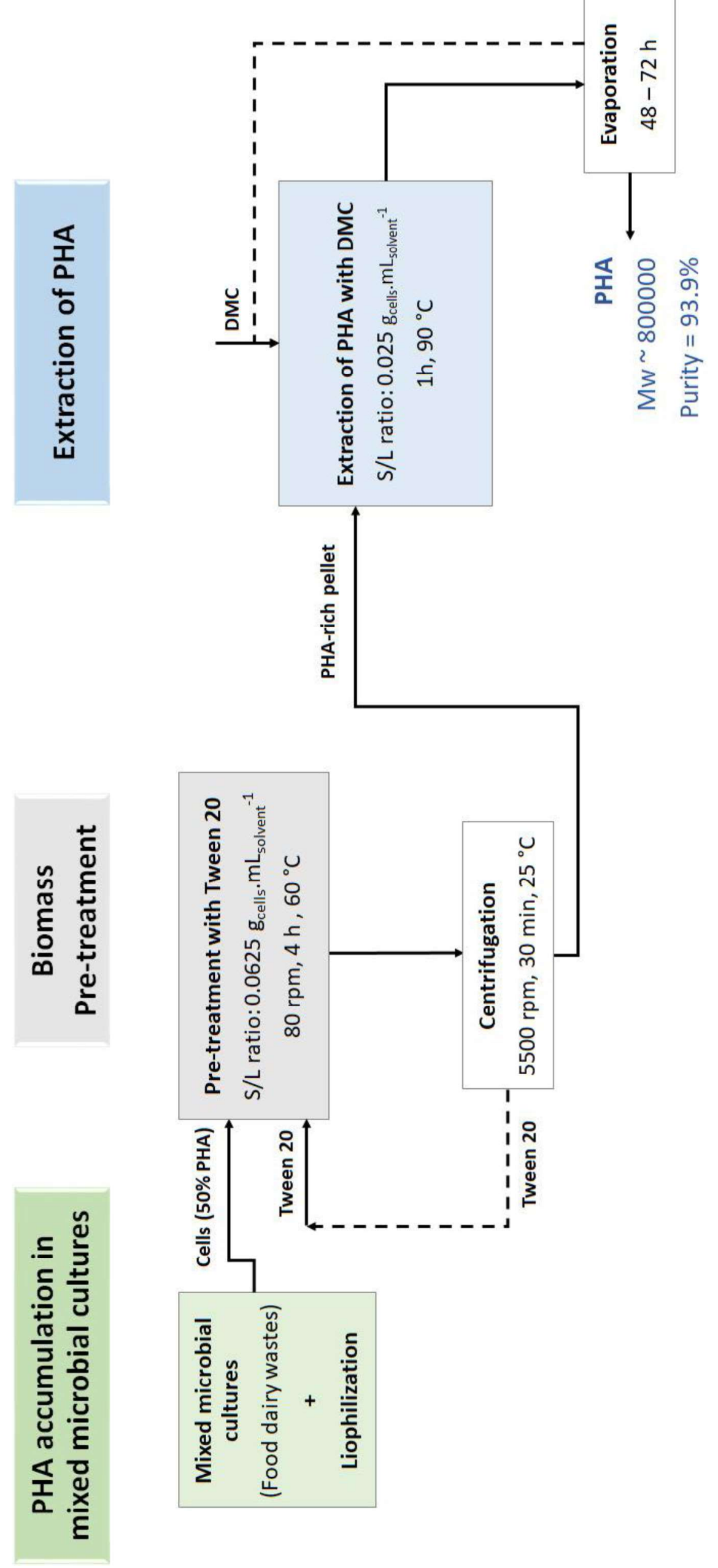

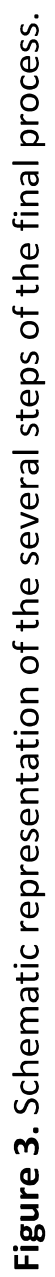




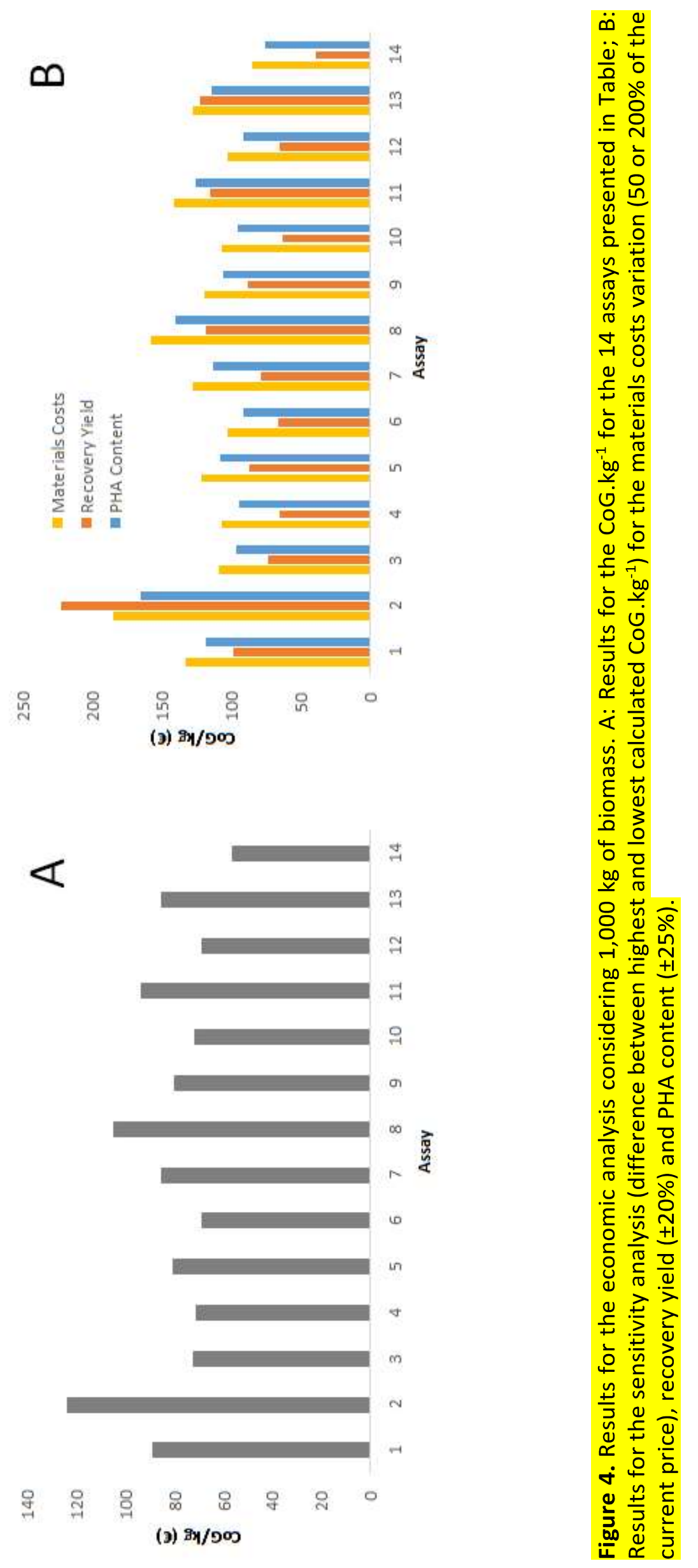




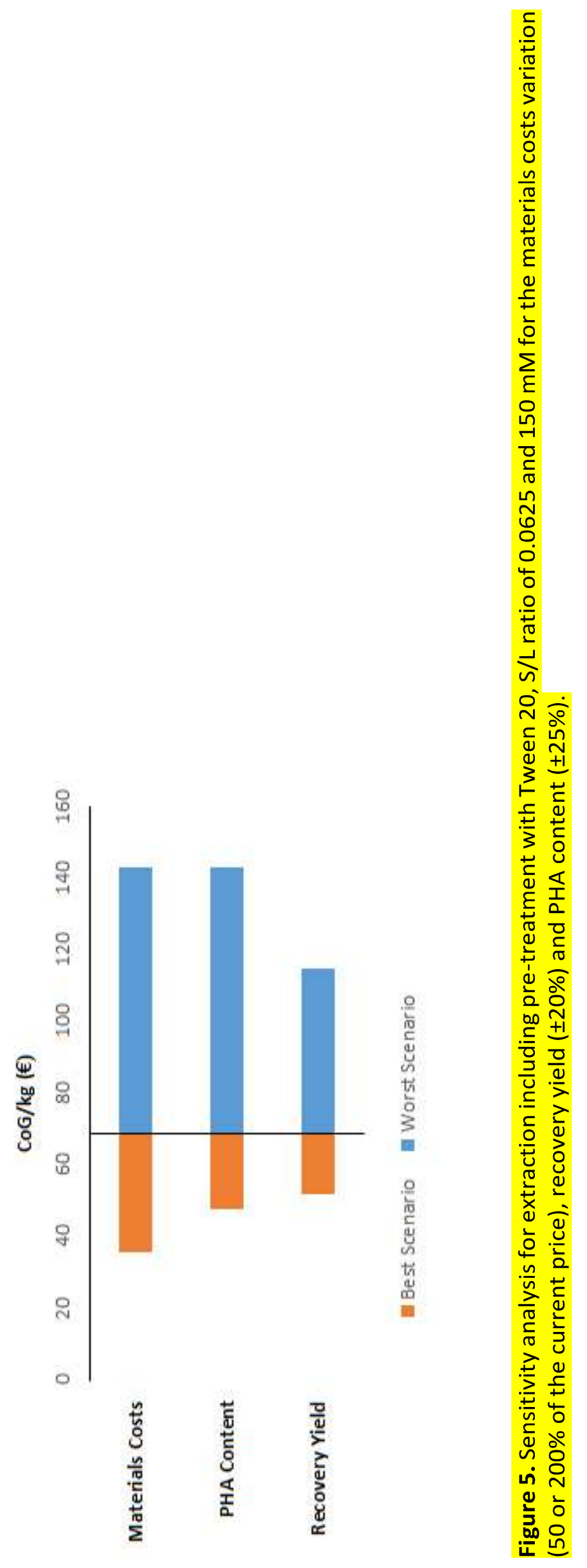




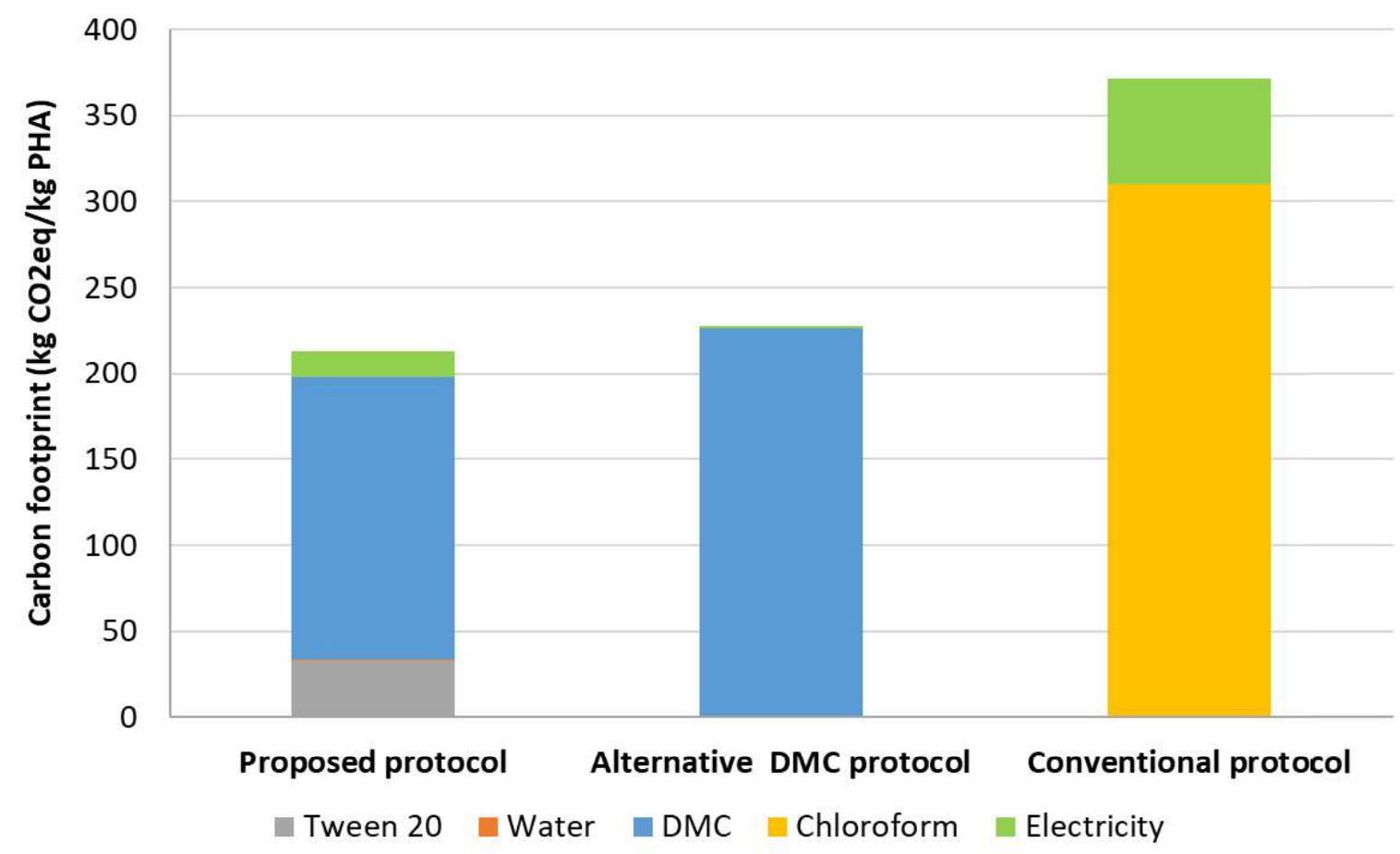

Figure 6. The carbon footprint for the proposed protocol (meaning final process depicted in Figure 3), for the protocol using only DMC and for the conventional process using chloroform. 
TABLES

Table 1. Overview of current extraction procedures for PHA produced by mixed cultures and characteristics of the extracted polymer.

\begin{tabular}{|c|c|c|c|c|c|c|c|c|c|c|c|c|}
\hline Chemicals & \begin{tabular}{|l|} 
Operating \\
conditions
\end{tabular} & $\begin{array}{c}\text { Pretreatment } \\
\text { Step }\end{array}$ & Purification Step & $\begin{array}{l}\text { HV } \\
(\%)\end{array}$ & $\begin{array}{l}\text { Recovery } \\
\text { yield (\%) }\end{array}$ & $\begin{array}{l}\text { Purity } \\
(\%)\end{array}$ & $\begin{array}{c}\mathrm{MW} \\
\text { (MDa) }\end{array}$ & PDI & $\mathrm{T}_{\mathrm{d}}\left({ }^{\circ} \mathrm{C}\right)$ & $\mathrm{T}_{\mathrm{m}}\left({ }^{\circ} \mathrm{C}\right)$ & $\mathrm{T}_{\mathrm{g}}\left({ }^{\circ} \mathrm{C}\right)$ & Ref. \\
\hline $\mathrm{CH}_{2} \mathrm{Cl}_{2}$ & $50^{\circ} \mathrm{C} ; 4 \mathrm{~h}$ & - & - & 20 & $52 \pm 1$ & 94 & 1.4 & 2.0 & 246 & n.r & n.r. & [2] \\
\hline $\begin{array}{l}\mathrm{CH}_{2} \mathrm{Cl}_{2}: \mathrm{H}_{2} \mathrm{O} \\
(8: 1)\end{array}$ & $\begin{array}{l}\text { Refluxing } \\
\text { (30 min) }\end{array}$ & $\begin{array}{l}\text { Acetone }(3 \mathrm{~h}, \\
\mathrm{rt})\end{array}$ & $\begin{array}{l}\text { Precipitation with } \\
\text { hot } \mathrm{H}_{2} \mathrm{O}\end{array}$ & 8 & 30 & - & 2.3 & 1.3 & n.r & 157 & n.r & [5] \\
\hline $\begin{array}{l}\mathrm{CHCl}_{3}: \mathrm{NaClO} \\
\left(6 \% \mathrm{Cl}_{2}\right)(1: 1)\end{array}$ & $\begin{array}{l}37^{\circ} \mathrm{C} ; 3 \mathrm{~h} ; \\
300 \mathrm{rpm}\end{array}$ & - & $\begin{array}{l}\text { Precipitation with } \\
\mathrm{MeOH}: \mathrm{CHCl}_{3}(9: 1) \\
\text { and oil } \\
\text { saponification with } \\
\text { hexane }\end{array}$ & 0 & $>90$ & $>90$ & 2 & 2.8 & n.r & n.r & n.r. & [4] \\
\hline $\begin{array}{l}\mathrm{NaClO}(5 \% \\
\left.\mathrm{Cl}_{2}\right)\end{array}$ & $\mathrm{rt} ; 24 \mathrm{~h}$ & - & - & 12 & $100 \pm 5$ & $98 \pm 5$ & $\begin{array}{l}0.34- \\
0.54 \\
\end{array}$ & $4-10$ & $\begin{array}{r}281- \\
291 \\
\end{array}$ & 153 & 0 & [9] \\
\hline $\mathrm{NH}_{3}(0.2 \mathrm{M})$ & $\begin{array}{l}115^{\circ} \mathrm{C} ; 0.5 \\
\mathrm{~h}\end{array}$ & Sonication & - & 13 & 92 & 86 & 0.6 & n.r & 307 & n.r. & n.r. & [10] \\
\hline $\begin{array}{l}\mathrm{NaOH}(0.2 \\
\mathrm{M})+\mathrm{SDS} \\
(0.2 \%)\end{array}$ & $\begin{array}{l}30^{\circ} \mathrm{C} ; 1 \mathrm{~h} ; \\
100 \mathrm{rpm}\end{array}$ & - & Washing with $\mathrm{H}_{2} \mathrm{O}$ & 0 & $91 \pm 5$ & $\begin{array}{c}99.1 \pm \\
0.5\end{array}$ & 0.48 & n.r & n.r & n.r. & n.r. & [17] \\
\hline SDS (0.12 M) & $90^{\circ} \mathrm{C} ; 3 \mathrm{~h}$ & - & $\begin{array}{l}\text { Washing with } \mathrm{H}_{2} \mathrm{O} \\
\text { and EtOH }\end{array}$ & 20 & $67 \pm 4$ & $56 \pm 7$ & n.r. & n.r. & n.r. & n.r. & n.r. & [18] \\
\hline DMC & $90^{\circ} \mathrm{C} ; 1 \mathrm{~h}$ & - & - & 20 & $49 \pm 2$ & 98 & 1.3 & 1.9 & 254 & n.r & n.r. & [2] \\
\hline DMC & $90^{\circ} \mathrm{C}, 1 \mathrm{~h}$ & $\mathrm{NaClO}(1 \mathrm{~h}, \mathrm{rt})$ & - & 20 & $76 \pm 4$ & 88 & 0.6 & 2.3 & 238 & n.r. & n.r. & [2] \\
\hline DMC & $90^{\circ} \mathrm{C}, 1 \mathrm{~h}$ & $\begin{array}{l}\mathrm{NaClO}(1 \mathrm{~h}, \\
\left.100^{\circ} \mathrm{C}\right)\end{array}$ & - & 20 & $82 \pm 3$ & 93 & 0.2 & 2.5 & 281 & n.r. & n.r. & [2] \\
\hline DMC & $90^{\circ} \mathrm{C} ; 1 \mathrm{~h}$ & Tween 20 & - & 9 & $53 \pm 2$ & 93.9 & 0.8 & 1.99 & \begin{tabular}{|c|}
255.3 \\
8
\end{tabular} & $\begin{array}{c}145.6 \\
9\end{array}$ & -7.33 & $\begin{array}{l}\text { This } \\
\text { study }\end{array}$ \\
\hline
\end{tabular}

n.r. - Not reported; rt - Room temperature 
Table 2. Conditions, recovery yield (\%) and ANOVA results of the extractions performed.

\begin{tabular}{|c|c|c|c|c|c|c|}
\hline Assay & Surfactant & $\begin{array}{l}\text { Surfactant Concentration } \\
\left(\mathrm{mmol} \mathrm{L}^{-1}\right)\end{array}$ & \begin{tabular}{|l|} 
Pre-treatment step \\
S/L ratio $\left(\mathrm{g}_{\text {cells }} \cdot \mathrm{mL}_{\text {solvent }}{ }^{-1}\right)$ \\
\end{tabular} & $\begin{array}{l}\text { PHA extraction with DMC } \\
\mathrm{S} / \mathrm{L} \text { ratio }\left(\mathrm{g}_{\text {cells }} \cdot \mathrm{mL}_{\text {solvent }}{ }^{-1}\right)\end{array}$ & $\begin{array}{l}\text { PHA } \\
\text { Recovery Yield (\%) } \\
\end{array}$ & ANOVA* \\
\hline 1 & Tween ${ }^{\otimes} 20$ & \multirow{6}{*}{100} & \multirow{3}{*}{0.03} & \multirow{6}{*}{0.025} & $45 \pm 4$ & BC \\
\hline 2 & Triton $^{\mathrm{TM}} \mathrm{X}-114$ & & & & $34 \pm 5$ & A \\
\hline 3 & Brij $^{\boxplus}$ L4 & & & & $48 \pm 2$ & $\mathrm{BCD}$ \\
\hline 4 & Tween $^{\circledR} 20$ & & \multirow{3}{*}{0.0625} & & $51 \pm 4$ & $C D$ \\
\hline 5 & Triton $^{T M} \mathrm{X}-114$ & & & & $46 \pm 1$ & $\mathrm{BCD}$ \\
\hline 6 & $\mathrm{Brij}^{\oplus} \mathrm{L} 4$ & & & & $49.2 \pm 0.4$ & $\mathrm{BCD}$ \\
\hline 7 & Tween $^{\circledR} 20$ & \multirow{7}{*}{150} & \multirow{3}{*}{0.03} & \multirow{6}{*}{0.025} & $51 \pm 4$ & $C D$ \\
\hline 8 & Triton $^{T M} \mathrm{X}-114$ & & & & $44.4 \pm 0.3$ & $B C$ \\
\hline 9 & $\mathrm{Brij}^{\otimes} \mathrm{L}^{4}$ & & & & $45 \pm 3$ & $\mathrm{BC}$ \\
\hline 10 & Tween ${ }^{\otimes} 20$ & & \multirow{3}{*}{0.0625} & & $53 \pm 2$ & D \\
\hline 11 & Triton $^{T M} \mathrm{X}-114$ & & & & $42 \pm 3$ & B \\
\hline 12 & $\mathrm{Brij}^{\otimes} \mathrm{L} 4$ & & & & $50 \pm 3$ & $\mathrm{CD}$ \\
\hline $\begin{array}{l}13 \\
14\end{array}$ & $\begin{array}{l}\text { Tween }^{\otimes} 20 \\
\text { Brij }^{\otimes} \text { L4 }\end{array}$ & & 0.0625 & 0.075 & $\begin{array}{l}30 \pm 0.9 \\
26 \pm 3\end{array}$ & - \\
\hline Control DMC & - & - & - & \multirow{2}{*}{0.025} & $38.4 \pm 0.8$ & - \\
\hline Control $\mathrm{CHCl}_{3}$ & - & - & - & & $63.5 \pm 0.7$ & - \\
\hline
\end{tabular}

*Averages followed by the same letter are not statistically different for a $\mathrm{p}<0.05$

Table 3. Data of molecular weight and polydispersity index of the PHA extracted after the process conditions optimization.

\begin{tabular}{clccr}
\hline Assay & \multicolumn{1}{c}{ Conditions* } & Recovery Yield (\%) & Mw (MDa) & Polydispersity Index (PDI) \\
\hline 10 & Tween 20; 0.0625; 0.025 & $53 \pm 2$ & $0.763 \pm 0.006$ & 1.99 \\
12 & Brij L; 0.0625; 0.025 & $50 \pm 3$ & $0.908 \pm 0.002$ & 1.85 \\
7 & Tween 20; 0.03; 0.025 & $51 \pm 4$ & $0.848 \pm 0.004$ & 1.88 \\
4 & Tween 20; 0.0625; 0.075 & $51 \pm 4$ & $0.788 \pm 0.002$ & 1.91
\end{tabular}

*Surfactant, pre-treatment step S/L ratio $\left(\mathrm{g}_{\text {cells }} \cdot \mathrm{mL}_{\text {solvent }}{ }^{-1}\right), \mathrm{PHA}$ extraction with DMC $\left(\mathrm{g}_{\text {cells. }} \cdot \mathrm{mL}_{\text {solvent }}{ }^{-1}\right)$; Number of repetitions, $\mathrm{n}=2$, for $\mathrm{Mw}$ and PDI determination

Table 4. Characteristics of the polymers extracted with Tween ${ }^{\oplus} 20$ and Brij ${ }^{\circledR} \mathrm{L} 4$ using the optimized conditions.

\begin{tabular}{lcc}
\hline Parameter & Tween $^{\circledR}$ 20 & Brij $^{\circledR}$ L4 \\
\hline $\mathrm{HV}(\%)$ & $9 \%$ & $9 \%$ \\
Purity (\%) by GC & 92.3 & 56.8 \\
Purity (\%) by TGA & 90.2 & 77.9 \\
$\mathrm{~T}_{\mathrm{g}}\left({ }^{\circ} \mathrm{C}\right)$ & -7.33 & -5.00 \\
$\mathrm{~T}_{\mathrm{m}}\left({ }^{\circ} \mathrm{C}\right)$ & 145.69 & 147.30 \\
$\mathrm{~T}_{\mathrm{d}}\left({ }^{\circ} \mathrm{C}\right)$ & & 242.62 \\
$\Delta \mathrm{H}_{\mathrm{m}}(\mathrm{J} / \mathrm{g})$ & 255.38 & 51.14 \\
$\mathrm{Crystallinity} \mathrm{( \% )}$ & 12.65 & 34 \\
$\mathrm{MW}(\mathrm{Da})$ & 9 & 908981 \\
$\mathrm{PDI}$ & 763259 & 1.85 \\
\hline
\end{tabular}




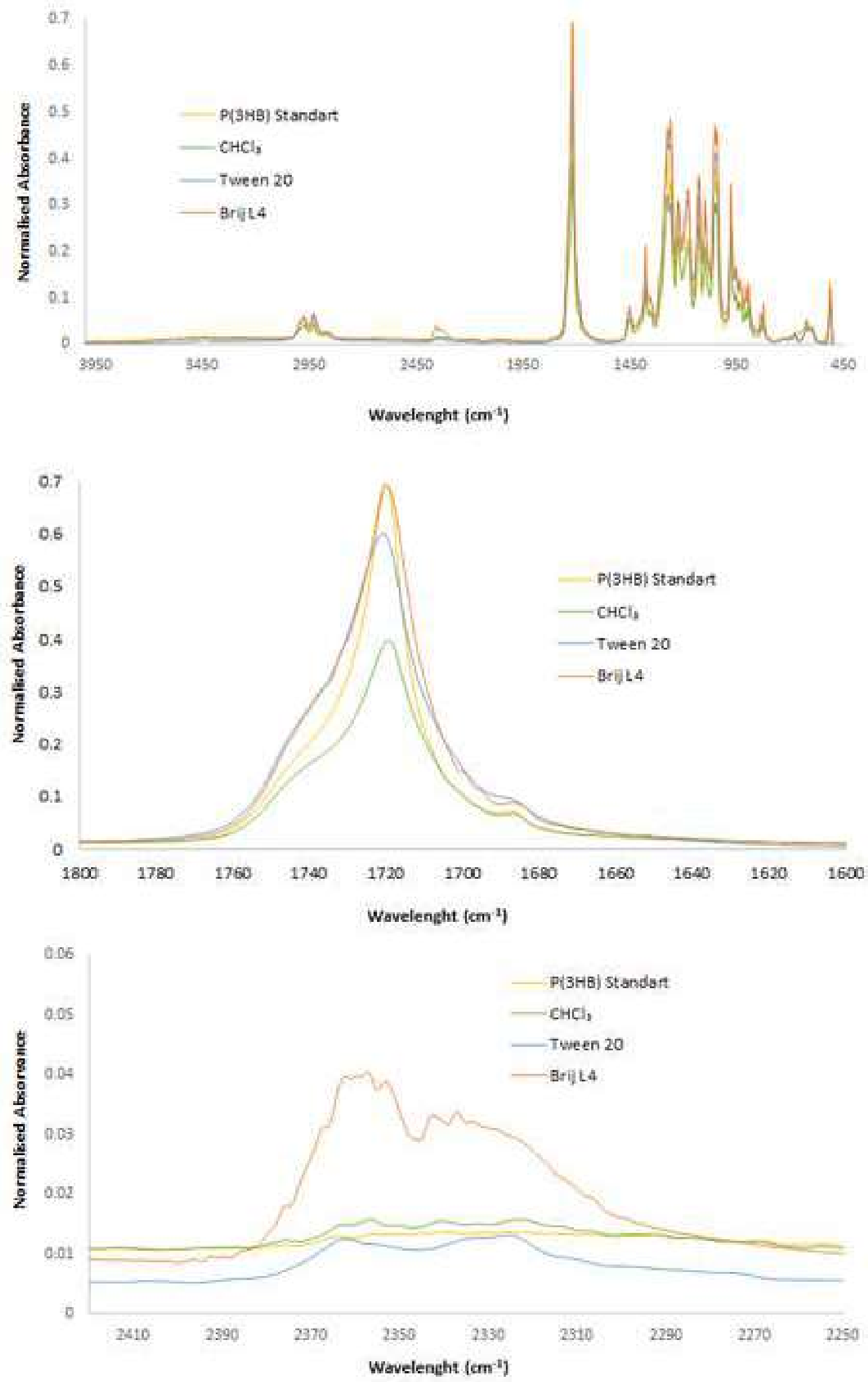

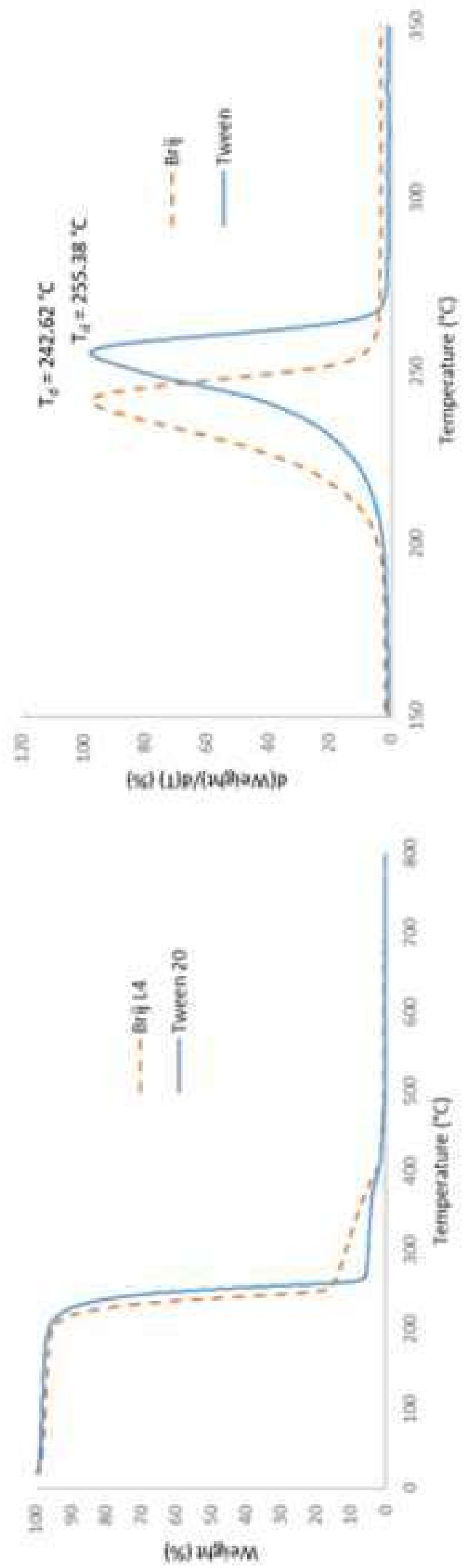

인 


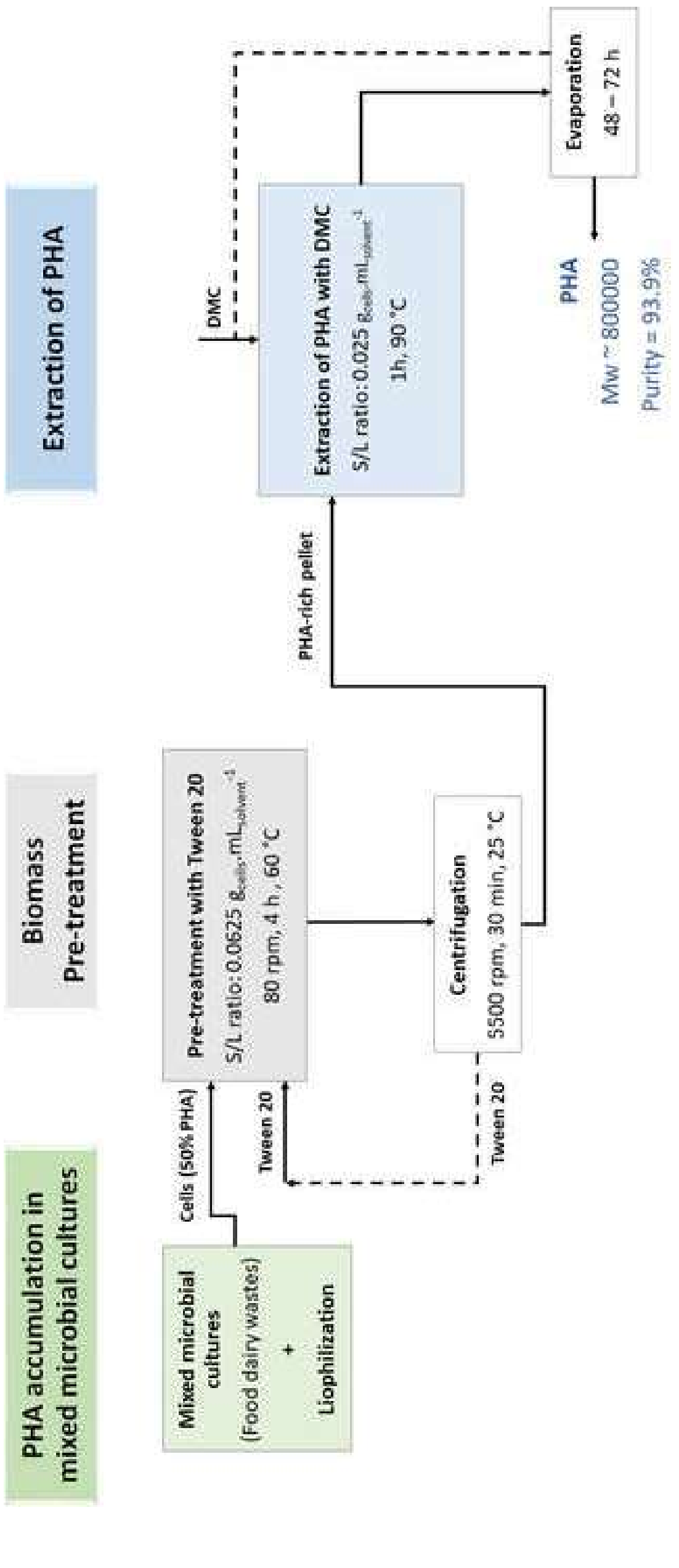




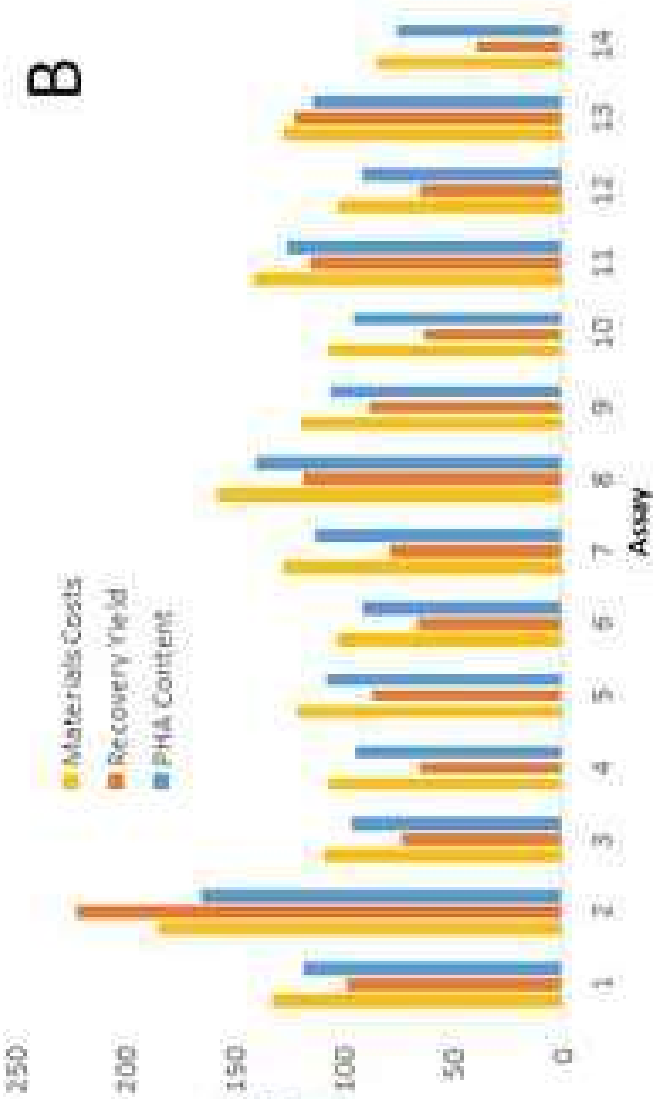

(3) $9 x / 200$

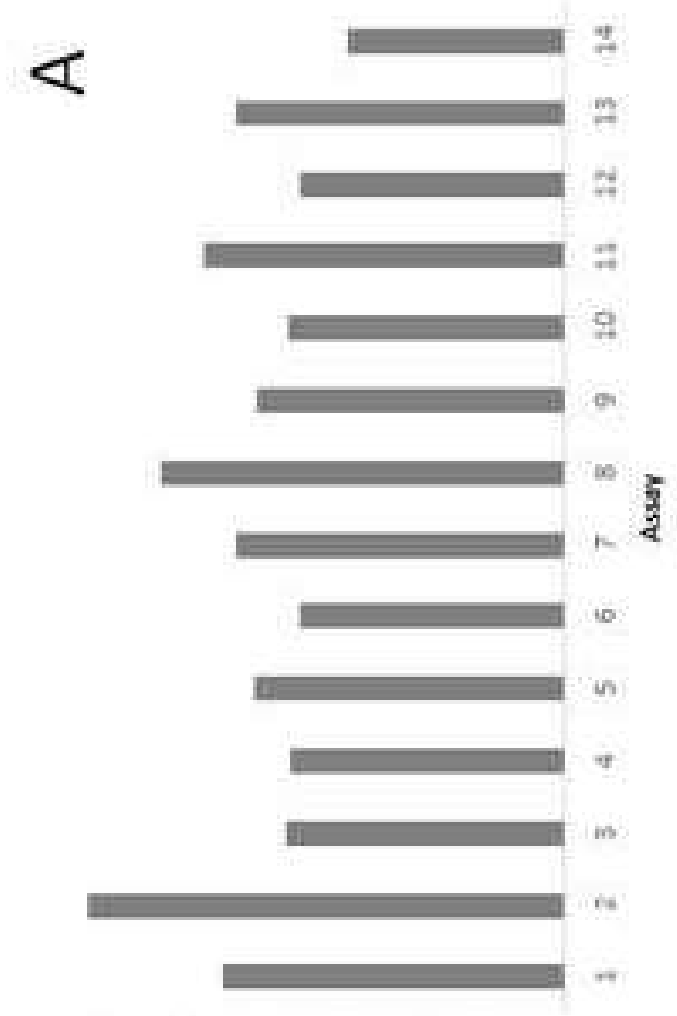

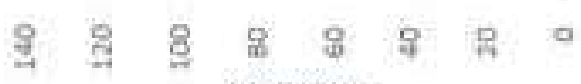

(a) $3 / / 5 \infty$

$\stackrel{00}{\frac{0}{2}}$ 


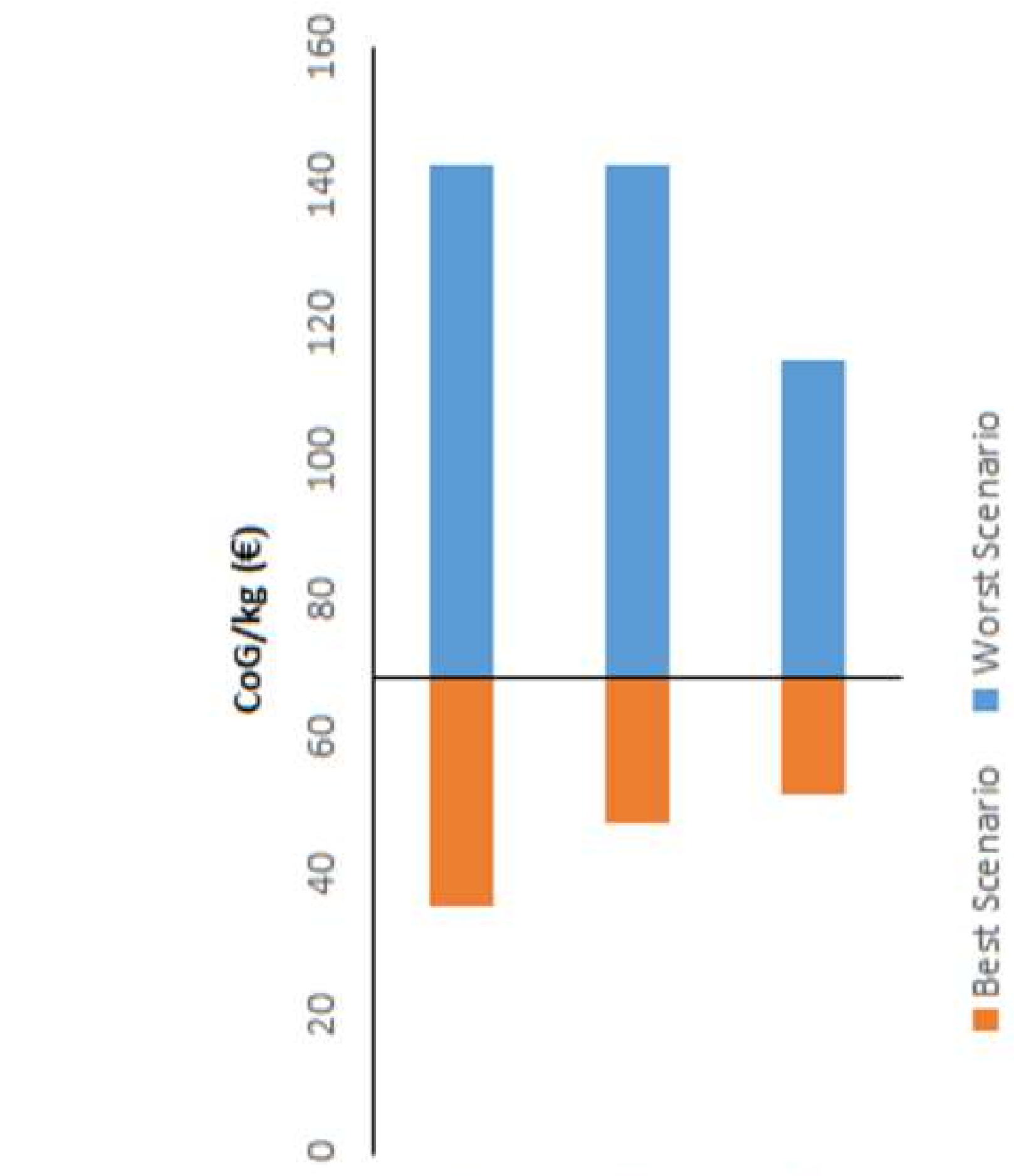

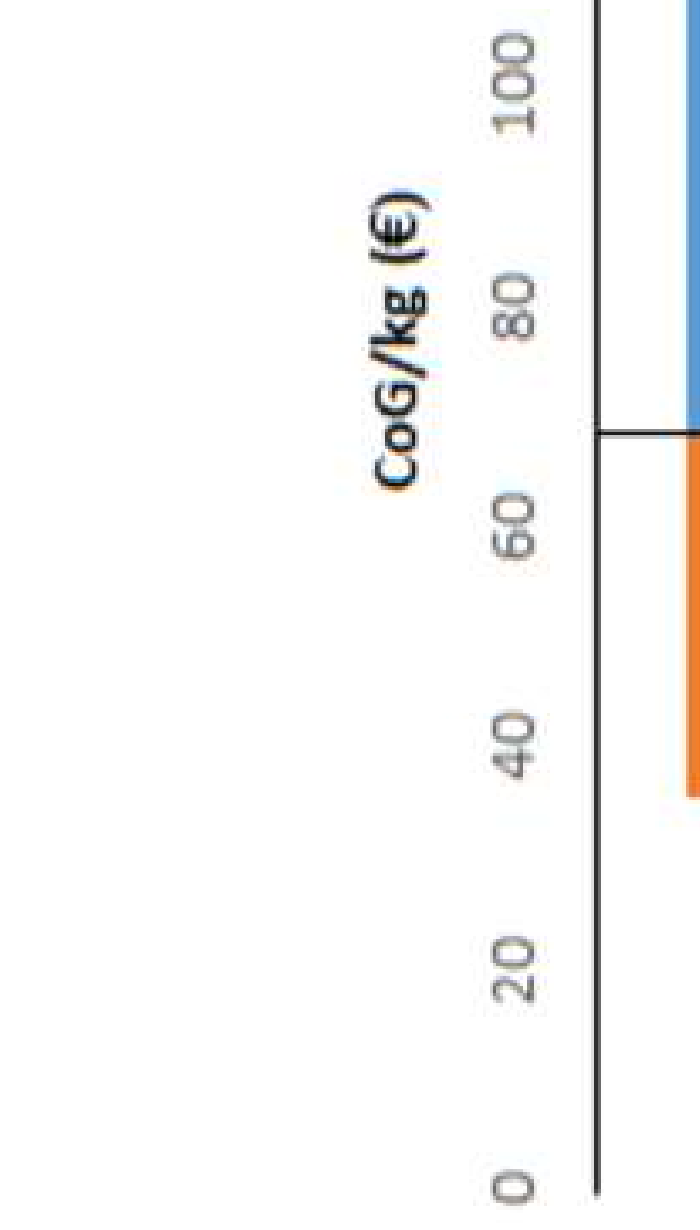

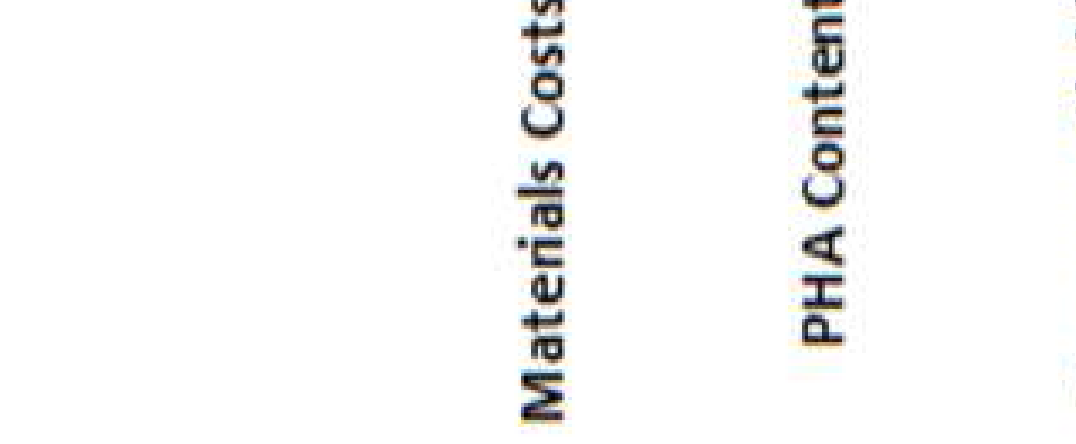




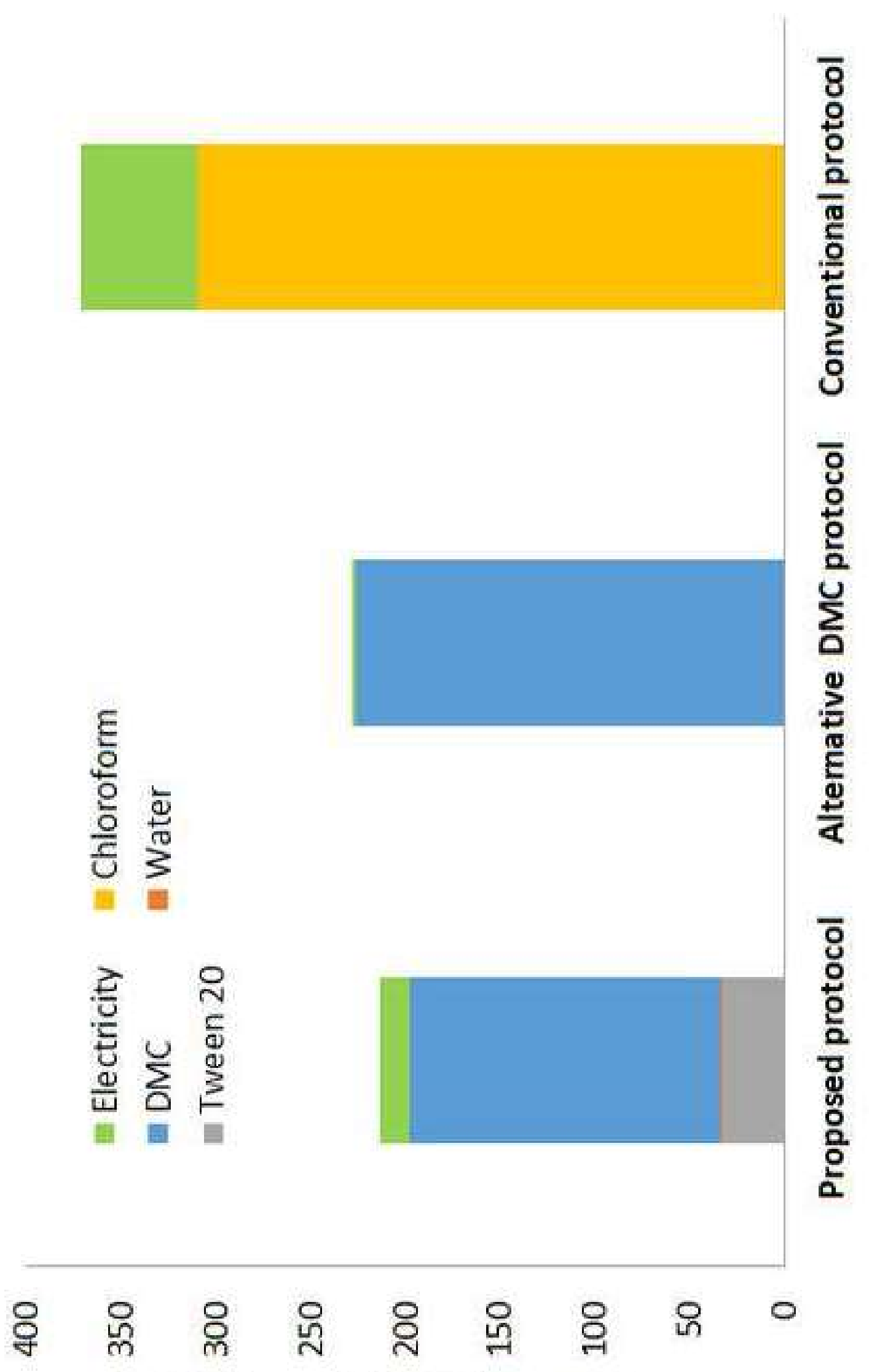

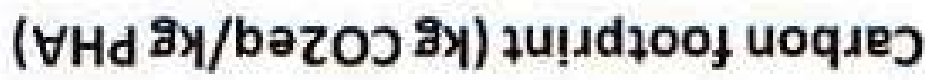

인 